\title{
Borde costero ciudad Antofagasta, Chile, visto como "interfase glocal"
}

\author{
Antofagasta City sea-side edge, in Chile, seen as "glocal interphase"
}

Recibido: diciembre 2019

Aceptado: septiembre 2020

\author{
María Adriana Gebauer Muñoz
}

\section{Resumen}

El objetivo de este artículo es, por una parte, presentar y proponer los lugares, que en el borde-costero de Antofagasta se pueden desarrollar como interfase entre lo global y lo local, a partir de considerar análisis y conclusiones de la cuarta, de cuatro dimensiones de abordaje de la Tesis Doctoral: "Centro Histórico como "interfase glocal" para la inserción de la ciudad intermedia en el sistema global de ciudades: Caso de estudio Antofagasta, Chile, 1990/2012" (Gebauer, 2015), considerando la importancia que, en esta ciudad, adquiere este borde cuando actúa y se configura como espacio mediador transnacional, y por otra, incorporar los conceptos de interfase glocal, Ciudad Intermedia, CH-ampliado, y ciudad-región ampliada, que fueron definidos por dicha Tesis. Desde el análisis de esta dimensión define los elementos de paisaje e imagen urbanos que son parte de la identidad urbana de esta ciudad y se pregunta qué de la imagen urbana que tiene el ciudadano, consolida o transforma la estructura espacial urbana de identidad vista desde el habitante, y encuentra en el mar y su borde, que son esenciales en la imagen de esta ciudad, los elementos que permiten que el borde-mar se constituya en "interfase glocal", y que al intervenirlo desde los Proyectos Estratégicos identificados en el borde, daría a la CI Antofagasta la posibilidad de trascender, si el borde-mar se aborda como un todo, desde su dimensión territorial que integra la totalidad de la ciudad, como un GPU, abonando con ello a su potencial inserción transnacional.

\section{Palabras Clave:}

Interfase glocal; ciudad intermedia; centro histórico ampliado; borde-mar

\begin{abstract}
The aim of this article is, on the one hand, to present and propose the places that in the sea-side of Antofagasta City could be developed as interphases between global and local, when considering the analyses and conclusions of the fourth of the approaches dimensions of the $\mathrm{PhD}$ Thesis "Historical Centre as "glocal interphase" for the insertion of the intermediate city in the global cities system: The Case of Antofagasta, Chile, 1990/2012" (Gebauer, 2015), with reference to the importance that the sea-side edge acquires when acts and configurates as transnational mediator space and, on the other hand, it attempts to incorporate the concepts of "glocal interphase", "intermediate city", "enlarged city-centre" and "enlarged city-region" that were defined by this research. From the analysis of this dimension it arrives to the landscape elements and urban images that are part of the urban identity of this city and it questions what of the urban image that the citizen has, it consolidates or it transforms the city spatial structure of identity seen from the inhabitant, and it finds in the sea and its edge, which are essential to this city identity, the elements that allow its constitution as "glocal interphase", and it proposes that, if the sea-side edge is approached from the Edge Strategic Projects identified, it would give to Antofagasta IC the possibility to transcend, if the sea-side edge is approached as a whole, from its territorial dimension, that integrates the totality of the city, as a GUP, contributing with this to its potential transnational insertion.
\end{abstract}

\section{Keywords:}

Glocal interphase; intermediate city; enlarged city centre; sea-side edge

\footnotetext{
1 Nacionalidad: chilena; adscripción: profesora-investigadora de la Facultad de Arquitectura y Diseño de la Universidad de la Salle en Pachuca estado de Hidalgo, México; Doctora en Ciudad, Territorio y Sustentabilidad, Universidad de Guadalajara, México; Master Arts en Diseño Urbano, Oxford Brookes University, UK; mgebauerm@gmail.com
} 


\section{INTRODUCCIÓN}

Las ciudades se han visto fuertemente impactadas, en su paisaje urbano, por efecto de la globalización y la ciudad de Antofagasta, objeto de estudio, no es ajena a esta situación que el presente artículo aborda cuestionando las transformaciones, de paisaje e imagen urbanos, que en la ciudad ocurren , a partir de considerar el análisis y conclusiones de la cuarta, de cuatro dimensiones de abordaje de la Tesis Doctoral: "Centro Histórico como "interfase glocal" para la inserción de la ciudad intermedia en el sistema global de ciudades: Caso de estudio Antofagasta, Chile, 1990/2012”' (Gebauer, 2015), preguntándose ¿qué de la imagen urbana que tiene el ciudadano, consolida o transforma la estructura espacial urbana de Identidad, vista desde el habitante?, centrándose en la importancia que adquiere el borde-costero en Antofagasta, si se constituye y configura como espacio mediador transnacional, pero arraigado con la identidad local, apoyándose en los conceptos que fueron definidos por dicha investigación, aportando con ello a una nueva mirada de los mismos.

\section{CONCEPTOS INCORPORADOS}

Estos conceptos que define la investigación aludida son: "interfase glocal", "Ciudad Intermedia", Centro Histórico Ampliado, Ciudad-Región Ampliada y se incorpora aquí parte del respaldo teórico que los sustenta para que se entienda el porqué de su pertinencia.

El primero de ellos "interfase glocal" (IG), como concepto y marco de referencia central para la inserción transnacional que dicha tesis propone para la Ciudad Intermedia y que se define como:

"Interfase glocal es el espacio, actividad o situación, que en símismacontiene la interacción de lo global y local, lo que se da tanto a nivel de flujos entre centros o ciudades de la red glocal; en la interacción de flujos de actividades económicas productivas de importancia glocal; en los aspectos de la morfología urbana que se consolidan como glocales y aportan a la estructura físico espacial glocal de identidad; $\mathrm{y}$ en los aspectos de paisaje e imagen urbanos que el habitante incorpora en los actos y lugares de la ciudad que se desarrollan a nivel glocal, con lo que consolida su estructura glocal de identidad. Su rol, en todas estas instancias, es mediar entre dos o más situaciones, las que pueden aludir a hechos, tanto propios de la localidad en que se inserta, como de universos distantes con los que se identifica y a los que evoca $\mathrm{y}$, aunque en ausencia, hace presente al ocurrir allí el "acontecimiento glocal". (Gebauer, 2015:159)

El término interfase, que encuentra su origen en las tecnologías de la comunicación, se ha abordado con distintos contenidos en diversas disciplinas, pero en todas ellas la condición de mediadora, entre materias distintas o situaciones diversas, es lo que prevalece y hace de la interfase un ente en sí mismo. De dichas aproximaciones es la formulada por Rubén Pesci (1993; 2010), la que la investigación de referencia selecciona porque es la única que otorga a la interfase una condición concreta que permite identificarla como un lugar específico, con características propias, que se relaciona con otro lugar y se puede dar en diversos niveles y escalas territoriales. Este autor, en su planteo, se refiere siempre a situaciones de contigüidad física en las localizaciones o espacios de mediación: rural/urbano; dentro/fuera; público/privado; exterior/interior; otras. En esta investigación se agrega a esta concepción la relación de espacios o situaciones distantes que interactúan a través del espacio ausente pero que dicha interacción se hace presente en un espacio o lugar físico concreto, en términos de Martín Heidegger (2009, 2010), las acciones allí se espacializan. Es esta condición la que permite dar existencia física al "espacio glocal", aquel que da cuenta de una interacción entre lo global y local, que puede ocurrir en la ausencia del sujeto actuante, haciendo con ello referencia a lo planteado por Anthony Giddens (2008:123) cuando se refiere a una presencia ausente. De este modo se liga la condición de mediador a distancia y los conceptos local y global en el concepto de "interfase glocal".

Lo "glocal", es un vocablo que dice de la unión de lo global y lo local a lo que se han referido autores como Roland Robertson (1992), Jordi Borja y Manuel Castells (1997) y Fernando Carrión (2002), siendo el primero quién acuñó el término glocalización. Para la presente conceptualización, además de lo antes dicho, se entiende lo glocal como el acontecer donde simultáneamente se está dando lo global y lo local en un mismo lugar o situación con lo que se genera 
el "acontecimiento glocal”. Por lo tanto, el lugar que se constituye como "interfase glocal" es un espacio que acoge el "acontecimiento glocal" y es en ello que el concepto aludido resulta innovador.

Un segundo concepto es el de "ciudad intermedia" (CI), como escala de análisis en este caso del borde costero de Antofagasta, y se define en los siguientes términos:

"Ciudad Intermedia es aquella ciudad media que actúa como intermediaria, no con arreglo a su talla demográfica y dimensiones determinadas, coherentes con su contexto geográfico, sino sobre todo, por la posición que ocupa o funciones que desempeñademediación,tantodelosflujos-bienes, información, innovación, administración, etc,-, entre los territorios urbanos y rurales; y urbanos de su área de influencia y los otros centros o áreas, más o menos alejados: subnacionales, nacionales, regionales o internacionales con los que interactúa-, como también, funciones de intermediación entre los espacios locales/ territoriales y los espacios regionales; nacionales e incluso globales. La intermediación puede ser demográfica, económica, política e institucional, incide tanto en la población endógena como exógena, características medio ambientales, administrativo-territoriales, social y cultural que se dan en las diversas escalas en que la ciudad participa." (Gebauer, 2015: 117)

En términos del estudio de inserción de las ciudades intermedias en la globalización, que postula la tesis de referencia, las transformaciones en Latinoamérica se pueden visualizar desde distintas perspectivas y escalas, muchas veces superpuestas (González, 2005). En el caso de la ciudad de Antofagasta y su Región, si bien se presentan distintos niveles de acción y, en ella, se agudizan desigualdades sociales en aspectos como, diferencias de estándares de empleo del sector exportador respecto del resto de los empleos, sin embargo, a nivel de la totalidad se observa una disminución importante en el desempleo regional. La acción en distintos planos y escalas, que la investigación de referencia aborda, muestra que a nivel de la Región, como un todo, en relación a otras regiones del país, ésta se favorece con el crecimiento económico de las últimas décadas, lo que se traduce en mejores niveles de escolaridad y educación, en mejoras en equipamientos de Salud y Educación Superior, como también en el mayor PIB regional en relación al promedio país, como lo corroboran Garcés Feliú, O’Brien y Cooper (2010), lo cual va en beneficio de la población regional, aspecto que se podría capitalizar positivamente, si el Estado aportara en una mejor distribución de los beneficios de este avance económico, para con ello lograr una mejor calidad de vida urbana para el total de la población local.

Un tercer concepto es el de "centro histórico ampliado" (CHA), que se define en los siguientes términos:

"Centro histórico ampliado" (CHA), es "el CH de origen de toda $\mathrm{CI}$, que puede ser entendida como ciudad-región, en donde el $\mathrm{CH}$ de origen de la ciudad crece y se desarrolla a partir de sus ejes estructurantes de tal modo que se genera un crecimiento tentacular del mismo, donde se localizan actividades y residencia habitualmente densa, que derivan del centro de origen y lo siguen teniendo como su lugar central de referencia, tanto simbólica como de uso, especialmente en lo que se refiere a las actividades de mayor jerarquía de la ciudad, como también de la región, de la cual son cabecera y con la cual se identifican." (Gebauer, 2015:368)

Los procesos de globalización, que han sido analizados preferentemente a nivel de las metrópolis latinoamericanas (Castells, 2001; De Mattos, 1999 y 2002; Sassen, 2003 y 2010) también repercuten en el sistema de ciudades-región que comprometen paisajes y recursos naturales de importancia. No obstante, en lo urbano, en las ciudades de tamaño medio y menores, el $\mathrm{CH}$ sigue siendo el depositario de la identidad de la ciudad porque tiene representatividad y simbolismo que lo hace ser el mejor lugar donde se puede materializar la presencia de cualquier enlace con la globalización (Silva, 2003), desde "lo glocal". A pesar de ello, el CH, especialmente en ciudades extractivas o industriales, aparece como obsoleto, deteriorado o subutilizado por sus habitantes, que privilegian, para su uso, los espacios de la globalización, como Shopping Malls y otros, que también se hacen presente en el caso del $\mathrm{CH}$ de Antofagasta y su extensión al Sur.

A diferencia del nivel metropolitano, el CH de la CI se caracteriza por identificar a la ciudad como un todo y es en este nivel, donde hay que actuar puesto que los $\mathrm{CHs}$ siguen teniendo un grado 
de centralidad urbana e histórica importantes, a la vez, que ser reconocidos como tal por sus habitantes como parte de su identidad de origen, por lo que sería importante, en el contexto de las grandes intervenciones, plantear un Gran Proyecto Urbano (GPU), Carrión, (2006), que pueda involucrar al $\mathrm{CH}$ como un todo, puesto que es en esta dimensión de totalidad, donde la intervención local tiene la posibilidad de trascender.

El cuarto concepto "ciudad-región ampliada" (CRA), se define como:

"Ciudad-región ampliada es el espacio de extensión variable en el que se integran varios territorios, ya sean nacionales como subnacionales, regionales, interregionales, e incluso internacionales, que compartiendo proximidad geográfica, desarrollan relaciones de cooperación en alguno de los aspectos singulares que la región involucrada posee, ya sea en sus recursos naturales, económicos, sociales o culturales, pero que, al mismo tiempo se relaciona con territorios distantes con los que mantiene y desarrolla conexiones glocales a partir de las específicas funciones globales que le son propias, y que son aquellas a través de las cuales se inserta transnacionalmente" (Gebauer, 2015: 118)
Profundizando en el concepto de "interfase glocal" (IG), con que se aborda la ciudad en la investigación de origen, graficadas en Diagrama $N^{\circ} 1$, las cuatro dimensiones que lo definen, se refieren en términos de Manuel Castells, a dos entradas que a veces se contraponen, la de los flujos que dice de lo global, y la de los lugares que hace presente lo local (Castells, 1997), que la tesis de referencia analiza desde los flujos, es decir, redes transnacionales en que la Región Antofagasta (RA) participa; y actividades productivas en que dicha región tiene ventajas competitivas; y por otra, a partir de los lugares, que identifica tanto desde la morfología urbana de la ciudad y elementos identitarios de alcance internacional del centro histórico ampliado (CHA), de Antofagasta, como desde elementos de paisaje e imagen urbanos, que dicen de aquello que es significativo de la ciudad-región Antofagasta, en cuanto elementos que interactúan como "interfase glocal' en diferentes niveles y escalas.

La cuarta dimensión que aborda este concepto, lo hace desde la modificación de imagen y paisaje urbanos, que ocurren en Antofagasta, en respuesta a la globalización, y en este artículo, tomando el borde-costero como escenario y lugar específico de atención.

Esta transformación de imagen, que en la CI es aún incipiente, se estudia en Antofagasta, no

Diagrama 1. Cuatro dimensiones de análisis del concepto "interfase glocal" (IG), a modo de modelo

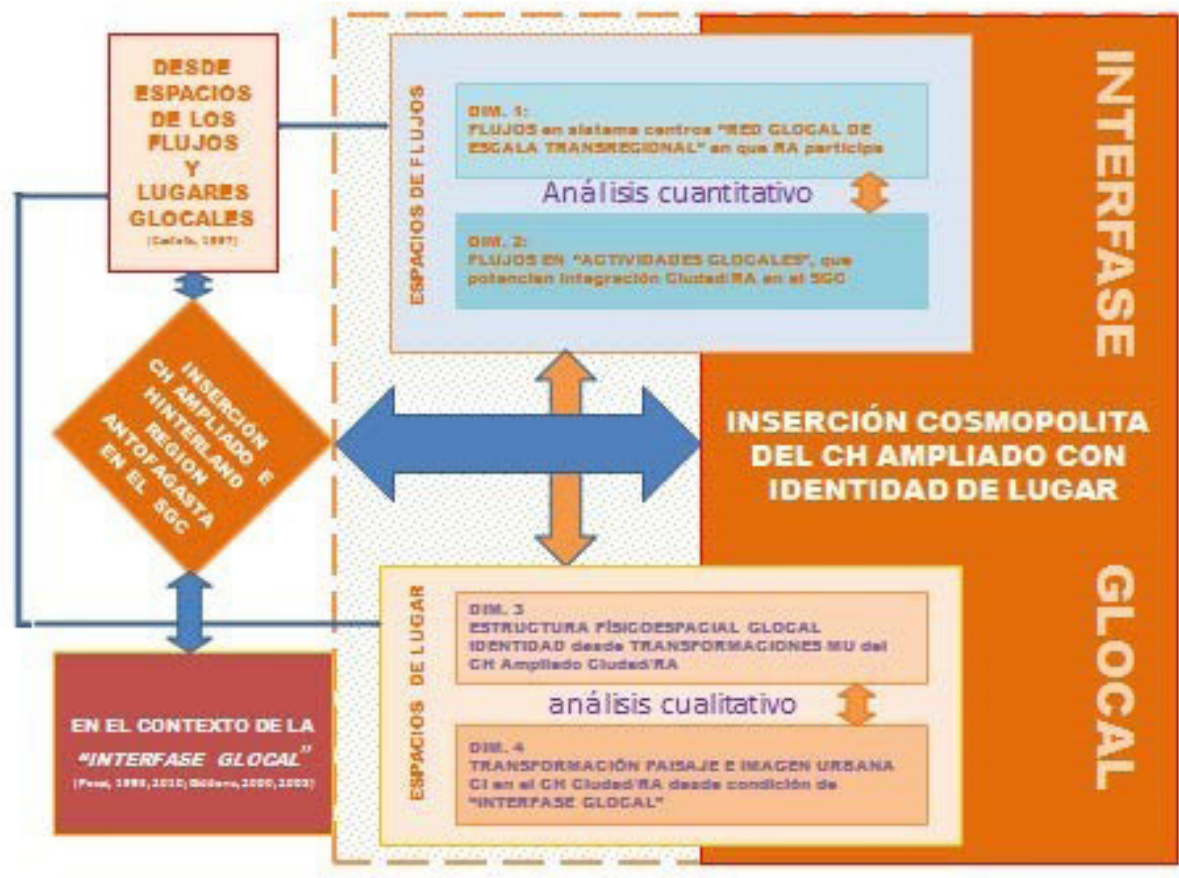

Fuente: Gebauer, 2015:78 
sólo en su forma aparente, sino se busca develar y exponer la estructura de ciudad desde la construcción de significado por parte del habitante y por lo mismo se trata de una aproximación cualitativa más que cuantitativa.

\section{APROXIMACIÓN METODOLÓGICA}

Metodológicamente, se consideró el resultado de encuesta realizada, como consulta ciudadana en diciembre 2012, por quién suscribe en conjunto con la Secretaría Comunal de Planificación (SECOPLAN)_Ilustre Municipalidad Antofagasta, a un grupo de 47 habitantes representativos de quienes habitan el centro de la ciudad. En ésta se incorpora la aproximación y categorías de Kevin Lynch (2013) y su reinterpretación por Pedro Brandâo (2011) y Carlos Martínez \& Caro Arrarás (2013), en un enfoque perceptivo del paisaje urbano. A ello se suma, la potencialidad que tiene la entrevista sistemática a profundidad (Taylor \& Bogdan, 1987; Varguillas \& Ribot, 2007), que se aplicó en este caso a un universo de treinta profesionales y agentes del desarrollo urbano, más doce entrevistas previas de acercamiento al tema, realizadas el segundo semestre de 2012.

Para Pedro Brandâo que reinterpreta la aproximación clásica de Kevin Lynch, "los valores de identidad del espacio público", se imponen a través de la "percepción social del valor identitario del espacio, esto es, a través de su reconocimiento como poseedor de un carácter único y especial” (Brandâo, 2011:49).
El paisaje y las transformaciones en la percepción del mismo, que emergen por aspectos que introduce la globalización, son analizados, a través de las categorías de sendas (calles), lugares (nodos) y edificios (hitos), a partir del distrito o área del Centro Histórico $(\mathrm{CH})$, de Antofagasta y su ciudad en busca de establecer cuál de ellos se consolidan como "elementos identitarios glocales", es decir, aquellos que siendo reconocidos localmente trascienden dicha localidad (Gebauer, 2015:90).

De estos, se seleccionan los elementos que se constituyen en identitarios para el ciudadano, (Nogué et al., 2009; Besse, 2000), y luego se los triangula con aquellos que surgieron desde la identificación de la estructura física de la ciudad en su $\mathrm{CH}$ ampliado, definidos en la tercera dimensión aludida (Gebauer, 2015:329-370), para posteriormente hacer una interpretación de significado de las mismas.

En Diagrama $N^{\circ} 2$ adjunto, se grafica este cruce de variables en que confluyen: Legibilidad vista desde categorías de: hitos, nodos y sendas (Lynch 1984, 20013; Brandâo, 2011), que se traducen, en consulta ciudadana, como edificios, lugares y calles; en estructura atípica y típica que, con el análisis morfológico (Rossi, 1992; Habraken, 1979; Samuels et al, 2013), se extrae la Estructura físico espacial glocal de identidad y en Significado: consolidado o transformado (Vidal \& Pol, 2005), interpretando las respuestas de la consulta ciudadana que ratifican o modifican la estructura físico espacial, antes mencionada.

Diagrama 2. Triangulación de aspectos que inciden en la definición de estructura identitaria vista desde el Habitante

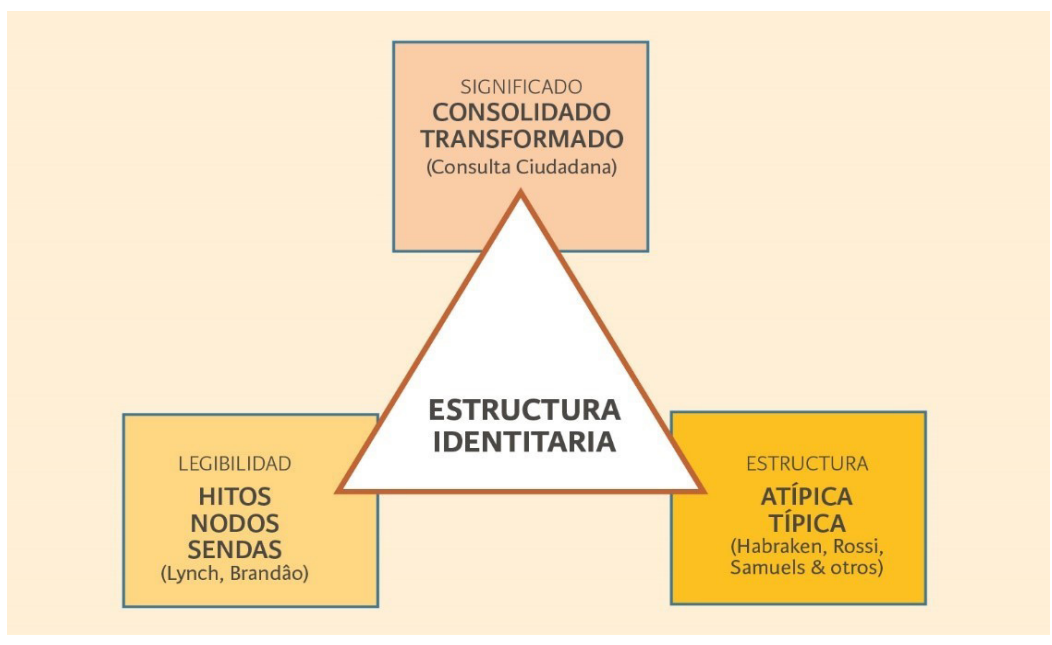

Fuente: Gebauer, 2015:377 
La consulta ciudadana que, constituyó un $60 \%$ de la muestra realizada, como trabajo de campo en 2012, complementa lo decantado a través de entrevistados: profesionales y agentes del desarrollo urbano, que constituyeron el $40 \%$ de la muestra trabajada. A través de esta consulta, se dilucidó la estructura espacial de identidad vista desde el habitante, utilizando las categorías indicadas de hitos, nodos y sendas, por lo que las preguntas se formularon incluyendo dichas categorías.

\section{ESTRUCTURA DE PAISAJE E IMAGEN DEL CH AMPLIADO DE ANTOFAGASTA VISTO COMO INTERFASE GLOCAL}

\author{
"El lugar de los habitantes no es aquel que \\ se deja ver, sino aquel que queda guardado \\ sin que se pueda ver directamente. Ese \\ territorio donde los ojos penetran con \\ dificultad, ahi donde el objeto se hace sujeto, \\ donde el espacio construido se transforma \\ en experiencia vivida para enriquecer la \\ memoria y su imaginación"
}

(Rábago,2006:17)

Analizar paisaje e imagen urbanos vistos por sus habitantes requiere incorporar, desde un inicio, el concepto de paisaje para el mundo contemporáneo. El ser humano, a pesar de la globalización, actúa y tiene una cultura territorial, y en ella el paisaje ejerce un rol social y cultural destacado, como lo expresan diversos autores.

El paisaje no es sólo el entorno natural, sino también lo construido y su entorno. En las aproximaciones al paisaje, en la historia moderna con el paisajismo geográfico que inaugura Humbolt, "combina magistralmente dimensiones naturales y culturales del mismo" (Ortega Canteros, 2004:24). En ello se da una asociación de ideas entre paisaje y región, que en la "landschraft geographie" alemana se emplean casi como sinónimos. Algo similar ocurre en la tradición geográfica francesa de finales del siglo XIX y principios del siglo XX. No obstante, es en la región, el lugar donde cristalizan las relaciones de naturaleza y cultura.

El paisaje, es "un área, tal y como la percibe la población, cuyo carácter es el resultado de interacción de factores naturales y humanos" (Nogué i Font et al., 2009:32). El paisaje no se concibe sin el observador, sea éste individual o colectivo, que con su mirada dota de sentido a un territorio determinado, lo que hace referencia a la acción comunicativa. En ella no sólo se transmite información sino se interactúa. respecto a lo cual, Joseph Gifreu afirma,

"la comunicación humana es un proceso histórico, simbólico e interactivo según el cual la realidad social es producida, compartida, conservada, controlada y transformada" (Gifreu, 1991:66-68).

El paisaje observado, se está convirtiendo, cada vez más, en producto de consumo como toda la producción actual, pero no hay que perder de vista, el valor original que éste tiene en su relación territorial. Norberto Muñiz, al referirse a los espacios de identidad de la ciudad puntualiza que:

"La identidad de las ciudades se articula en relación con atributos -singulares o múltiples-, que les confiere notoriedad en los intercambios económicos". De tal modo que "los ritos futuros de las ciudades occidentales girarán en torno a su posicionamiento en el mercado a partir de la exaltación de valores intangibles (calidad de vida, sostenibilidad, interactualidad, tolerancia, talento, innovación) vehiculados, [.....], a través de la creación de una imagen de marca que surge de la puesta en valor [....] del paisaje urbano." (Muñiz, 2007:151)

Respecto a identidades territoriales, Joan Nogué i Font et al., afirman:

“......el paisaje desempeña un papel relevante en el proceso de formación, consolidación y mantenimiento de identidades territoriales, $y$ en este sentido, deviene un argumento comunicativo central en estrategias de marketing de ciudades (city marketing) y de promoción turística, entre otras." [.....] "....la revalorización de los lugares y la creciente necesidad de singularizarse, de exhibir y destacar todos aquellos elementos significativos que distinguen un lugar respecto de los otros, y el paisaje es uno de esos elementos" (Nogué i Font et al.,2009:45)

En el caso del borde-costero de Antofagasta éste tiene una dimensión y extensión y características espaciales que integra a la ciudad como un todo, lo que permite potenciar su identidad territorial que es necesario considerar. 


\section{CENTRO HISTÓRICO AMPLIADO (CHA), Y APRONTES QUE EN EL BORDE-MAR TIENEN POTENCIAL DE CONVERTIRSE EN INTERFASE GLOCAL}

A partir de las definiciones incorporadas que la investigación referida entrega de interfase glocal (IG), de centro histórico ampliado (CHA), de redefinición de ciudad intermedia (CI), entendida ésta como una unidad con la región de la que es cabecera como ciudad-región ampliada (CRA) (Gebauer, 2015:159; 368; 117 y 118 respectivamente), el presente artículo propone avanzar en esta línea a través de definir estos lugares en cuanto a paisaje e imagen urbanos para luego proponer las condiciones de normativa de edificación que ayuden a configurar la imagen de $I G$ que trascienda internacionalmente tomando el CHA de Antofagasta como marco de referencia, y constituyéndolas en factor de gestión en el tiempo.

Estos lugares se proponen como un apronte a considerar, porque de ellos se tiene una base definida en la tesis de referencia, pero se requiere avanzar en trabajos específicos, aún no desarrollados, y en lo que esta presentación tiene como objetivo dejarlos planteados para su estudio futuro a profundidad.

Se incluyen las aproximaciones que comprometen la visión de paisaje que es en lo que se centra la cuarta dimensión de análisis que se está considerando.

\section{PRIMER APRONTE: ESTRUCTURA DE IDENTIDAD DE LA CIUDAD DESDE PERCEPCIÓN DE LOS HABITANTES CONSULTADOS}

Se utilizan respuestas a consulta ciudadana, tanto a través de mapas mentales como a coincidencias en definición de hitos (edificios significativos); nodos (lugares emblemáticos); y sendas (calles estructurantes). Como se menciona anteriormente, se consideraron las categorías de Lynch (2013), en términos de hitos, nodos y sendas, que para este autor son parte de lo que construye la imagen de la ciudad, junto con barrios o distritos, y bordes.

En términos de este autor por hitos se entiende:

“ .....un elemento de referencia que el individuo tiene en sus recorridos por la ciudad, los que no son importantes por la actividad, que al interior de ellos ocurre, sino por el valor de orientación que tienen, desde el exterior, para el transeúnte.” (Lynch, 2013: 63)
Para este autor, nodos son:

"Los puntos estratégicos de una ciudad a los que puede ingresar un observador y constituyen los focos intensivos de los que parte o a los que se encamina. Pueden ser cruces, o confluencia de una coyuntura en el transporte o simplemente condensación de determinados usos que los distingue, como una esquina o una plaza." (Lynch, 2013: 63)

Sendas, en expresión de Kevin Lynch:

“......son los conductos que sigue el observador normalmente, ocasionalmente o potencialmente. Pueden ser calles, senderos, líneas de tránsito, canales o vías férreas.” (Lynch, 2013:62)

Las conexiones viales son los elementos preponderantes que el ciudadano tiene en su imagen. Los transeúntes observan la ciudad mientras la recorren y navegan en ella, y estos recorridos organizan y conectan los demás elementos con que la persona imagina y usa la ciudad. Completan las cinco categorías de Kevin Lynch los bordes, que "son los límites entre dos fases, rupturas lineales de la continuidad [.....]", y los barrios $o$ distritos, que para este autor, "son las secciones [.....], concebidas como de un alcance bidimensional, en el que el observador entra "en su seno" mentalmente y que son reconocibles como si tuvieran un carácter común que los identifica" (Lynch, 2013:62). En el caso del CH Antofagasta, centro de origen de la ciudad, éste corresponde a un "barrio o distrito" según la definición precedente.

Las preguntas que se formulan, en la consulta ciudadana, se refieren a edificios (hitos), lugares (nodos), y calles (sendas) que, para el ciudadano, en su experiencia de la ciudad son importantes y con los cuales se identifica constituyéndose estos en los elementos que forman parte de su imagen.

\subsection{Edificios "hitos"}

La Gráfica $N^{\circ} 1$ adjunta, incluye las respuestas dadas por los habitantes consultados respecto de edificios que son importantes en su experiencia de la ciudad y que serían "hitos", en las categorías de Lynch mencionadas. Los edificios, incluidos en las respuestas, se refieren ya sea a 
edificios de carácter monumental e históricos, o a edificios institucionales representativos de la autoridad político-administrativa de la ciudad, o son referentes, en lo que percibe el transeúnte por su condición de altura, modernidad o densidad, y se constituyen en elementos de orientación en el deambular en el centro. Además, en términos numéricos de las respuestas, si se suman sus porcentajes y ubicaciones, estos se refieren a zonas de interés histórico, cívico, o de referencia respectivamente.

Los edificios hitos son:

- Barrio Histórico y entorno Plaza Colón, que es la plaza principal de inicios de la ciudad, que incluye los edificios de: Correos de Chile, recientemente remodelado y reciclado como Biblioteca Regional; Banco Santander; Banco Estado; Iglesia Catedral y Barrio Histórico en que se suman los edificios del FCAB; Museo Regional; Ex Aduana; y ex Resguardo Marítimo; y respuesta dada como barrio histórico, todo lo cual constituye un $43 \%$ de las respuestas. A ello se podría anexar las que indican el Mercado Municipal, en Plaza Sotomayor y su entorno, que constituye un $3 \%$ más, ya que es un edificio y lugar reconocidos como parte de la historia y memoria colectiva de Antofagasta.

- Edificios de representación cívica, constituidos por la Intendencia Regional, y edificio de la I. Municipalidad de Antofagasta, que son un $18 \%$ de las respuestas.

- Edificios en altura que constituyen hitos de orientación en el centro: Edificio Centenario, en torno a Plaza Colón; Edificio Paz de construcción en altura reciente; Obelisco y Edificio Curvo, estos tres últimos dan cuenta de la extensión ampliada del centro hacia el sur, en Avdas. Brasil y Angamos. En conjunto suman un $7 \%$ de las respuestas.

Para detectar la imagen de ciudad que el habitante tiene de la misma, se planteó también el uso de mapas mentales, que describen gráficamente lo que el/la encuestado/a observa como su imagen de ciudad. Estos mapas son utilizados, con frecuencia, en los estudios de imaginarios urbanos y resultan ser una herramienta valiosa en estudios etnográficos, (Narváez, 2010 y 2011).

Los mapas mentales incorporados en Figura $N^{\circ} 1$, muestran dos imágenes que complementan la gráfica anterior de lo percibido por los habitantes,

\section{Gráfica 1. Edificios de Antofagasta percibidos como importantes según consulta ciudadana, diciembre de 2012}

Fuente: Datos consulta ciudadana (Gebauer, 2015:381)

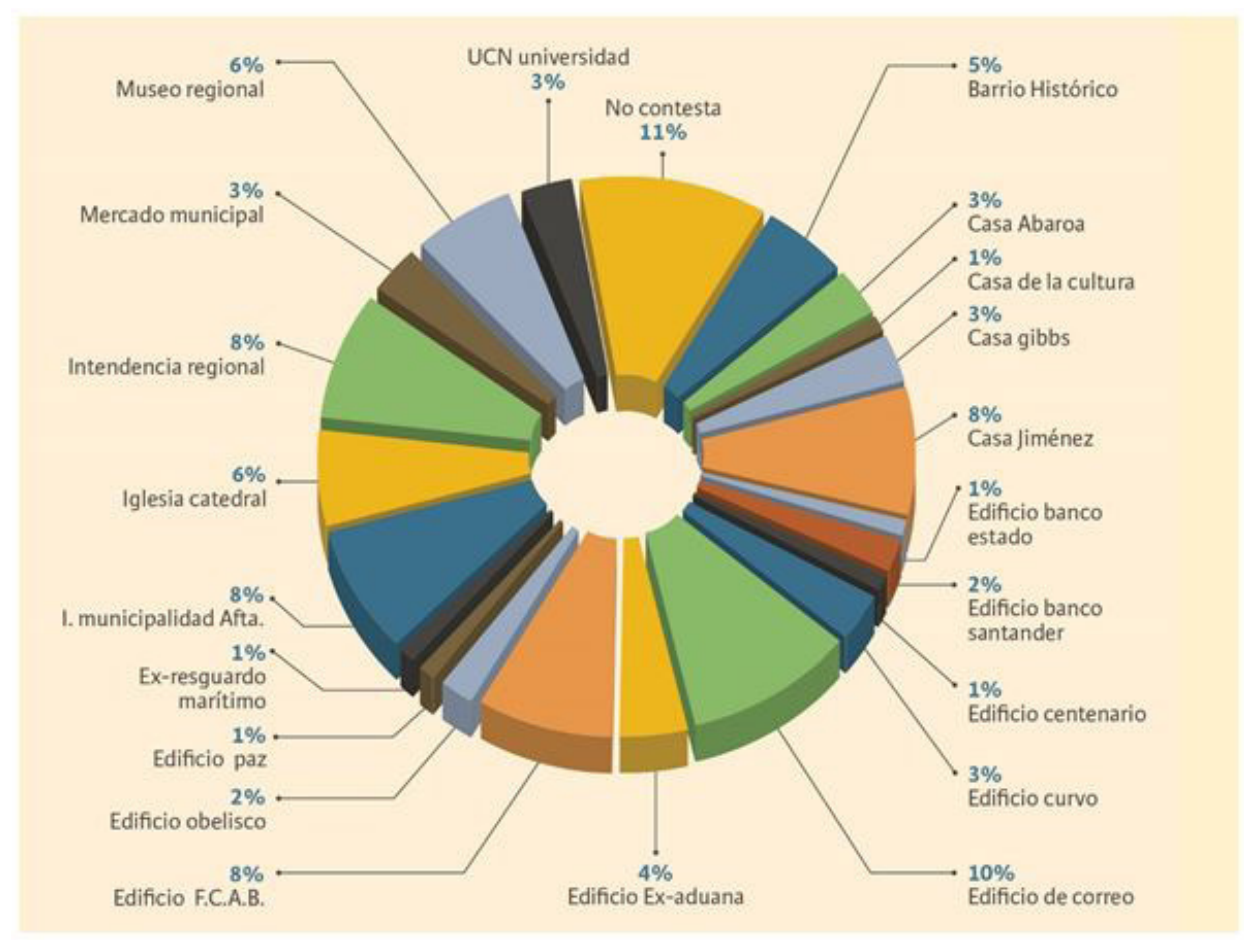


Figura 1. Mapas mentales residentes locales en consulta ciudadana respecto de elementos relevantes del centro histórico y ciudad de Antofagasta_diciembre de 2012_1
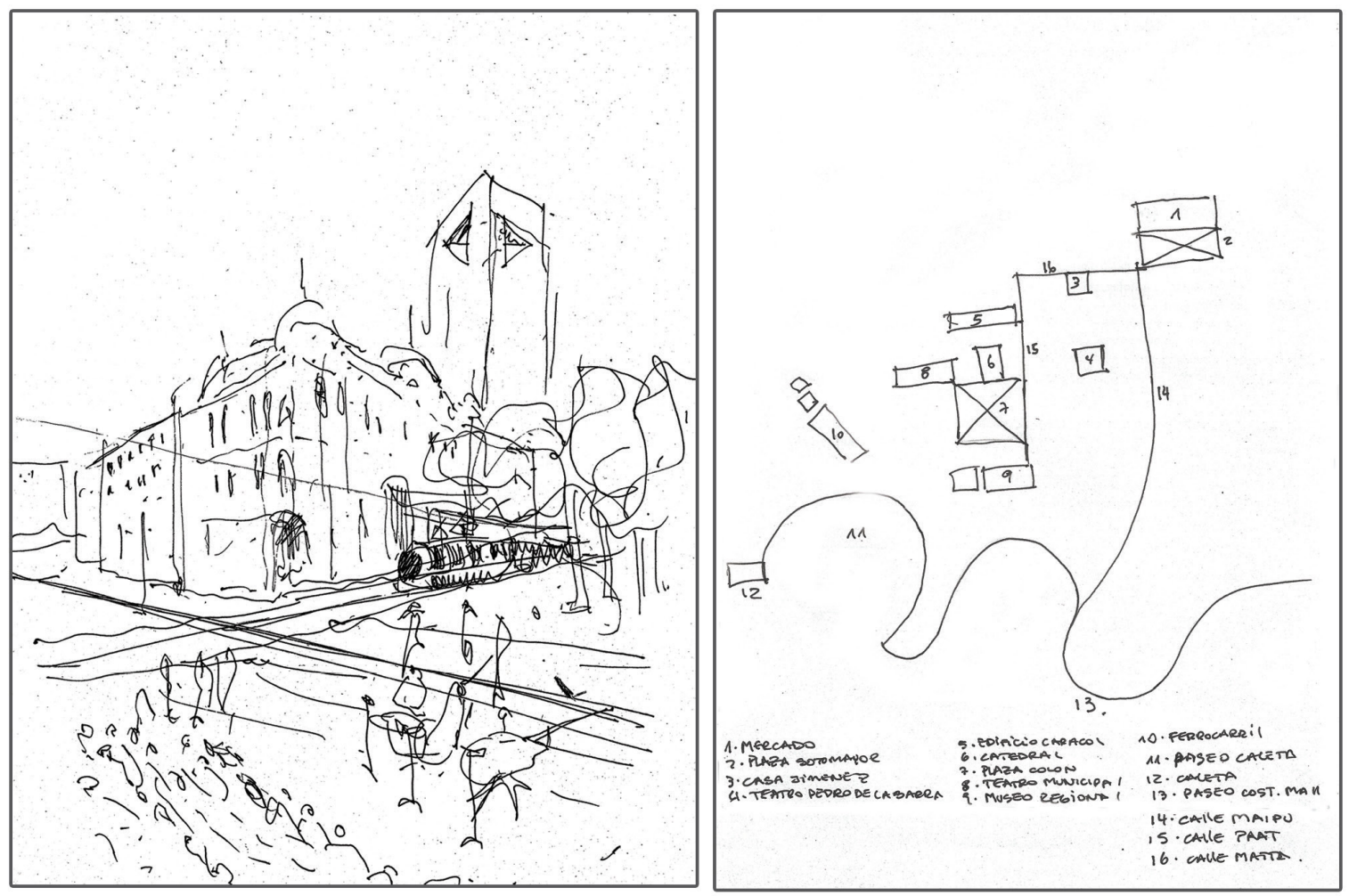

Fuente: Mapas mentales (Gebauer, 2015:382)

en cuanto a edificios que para los consultados son importantes. En el primer mapa aparece el edificio de Correos de Chile, hoy Biblioteca Regional, y Edificio Centenario, ambos configurando el frente poniente de la Plaza Colón, Plaza cívica de la ciudad de origen, que es parte fundamental de la estructura de identidad de la ciudad estudiada. En el segundo mapa, hay una localización esquemática de los edificios que, para la persona consultada, son importantes en el centro y también, aparecen listados los edificios que se incluyen en imagen previa, al mismo tiempo que se destaca el bordemar como lugar, junto con las Plazas: Colón y Sotomayor o del Mercado Municipal.

En relación al borde-costero, los mencionados son edificios hitos significativos que se visualizan desde la Costanera ya sea por su altura o por la abertura o vacío generado, por lo cual se los percibe desde el borde a través de sendas de conexión.

\subsection{Lugares "nodos"}

La Gráfica $N^{\circ} 2$ incluye los lugares de Antofagasta señalados como importantes por los ciudadanos consultados en la muestra, y que son "nodos" en las categorías de Lynch (2013), en donde, para efectos de interpretación de la gráfica, se integran los lugares ligados a un mismo espacio para facilitar, visualmente, su lectura. Es importante hacer notar que el mayor porcentaje de lugares señalados, fueron aquellos que se localizan a lo largo del borde marítimo, elemento de identidad morfológica y existencial de esta ciudad, antes nombrado.

A su vez, los mapas mentales, incorporados en respuestas de consulta ciudadana, que se muestran, en las dos imágenes de Figura $N^{\circ} 2$, complementan y ratifican la percepción que el habitante tiene de los lugares que son indicados como importantes para esta ciudad.

En la primera imagen, el mapa destaca el bordemar, por una parte, y los cerros de la Cordillera de la Costa, por otra, a la vez que se indican todos los lugares que para él/ella consultados 
son importantes. Destaca, en ellos, que aparece nuevamente identificada la configuración lineal de la ciudad como relevante.

En la segunda imagen, el mapa mental muestra tres elementos que son estructurantes en la ciudad: el mar, reconocido como elemento de identidad y pertenencia de esta ciudad; La Portada, conformación rocosa de sedimentos costeros, hito natural en el borde-mar norte e icono por el cual se identifica, publicitariamente, a esta ciudad; y el nuevo Edificio Consistorial que dice de la gestión administrativa actual de la ciudad.

El resultado de la consulta, en este tema, indica que se coincide en una estructura de lugares que incluyen y dan importancia al casco central de la ciudad (38\%), dentro de ello al Barrio Histórico como lugar, destacándose una sucesión de lugares en el borde marítimo (41\%), como también al sector de Avda. Brasil, con su extensión al Sur en Angamos y Ruinas de Huanchaca (8\%), que transversalmente también se conectan con el borde y se integran como sistema con él, los que sumados con el sistema de borde constituyen el $49 \%$, es decir casi la mitad de los consultados da primera importancia al borde-mar. Hay un $11 \%$ que no contesta o su respuesta es indefinida y un $2 \%$ que se refieren a Plaza Los Eventos o Bicentenario en forma puntual.

Con respecto a este borde, se menciona un sistema de lugares desde Caleta Coloso por el sur, con varios puntos intermedios dentro de los cuales se destaca el Paseo Costero, seguido de Playa Paraíso o Carboncillo y con menor porcentaje, Caleta Pesquera, en el borde-centro, hasta Playa Trocadero, en el norte de la ciudad. Todos los lugares, de borde costero señalados que, en conjunto, constituyen el paseo de borde, son el potencial espacio público principal de la ciudad y es el que tiene posibilidades de trascender internacionalmente.

Como se ha inferido, el borde-mar es señalado como lugar importante por un $49 \%$ de las respuestas

Gráfica 2. Visión integrada de "lugares" importantes en Antofagasta, según percepción consulta ciudadana_diciembre de 2012

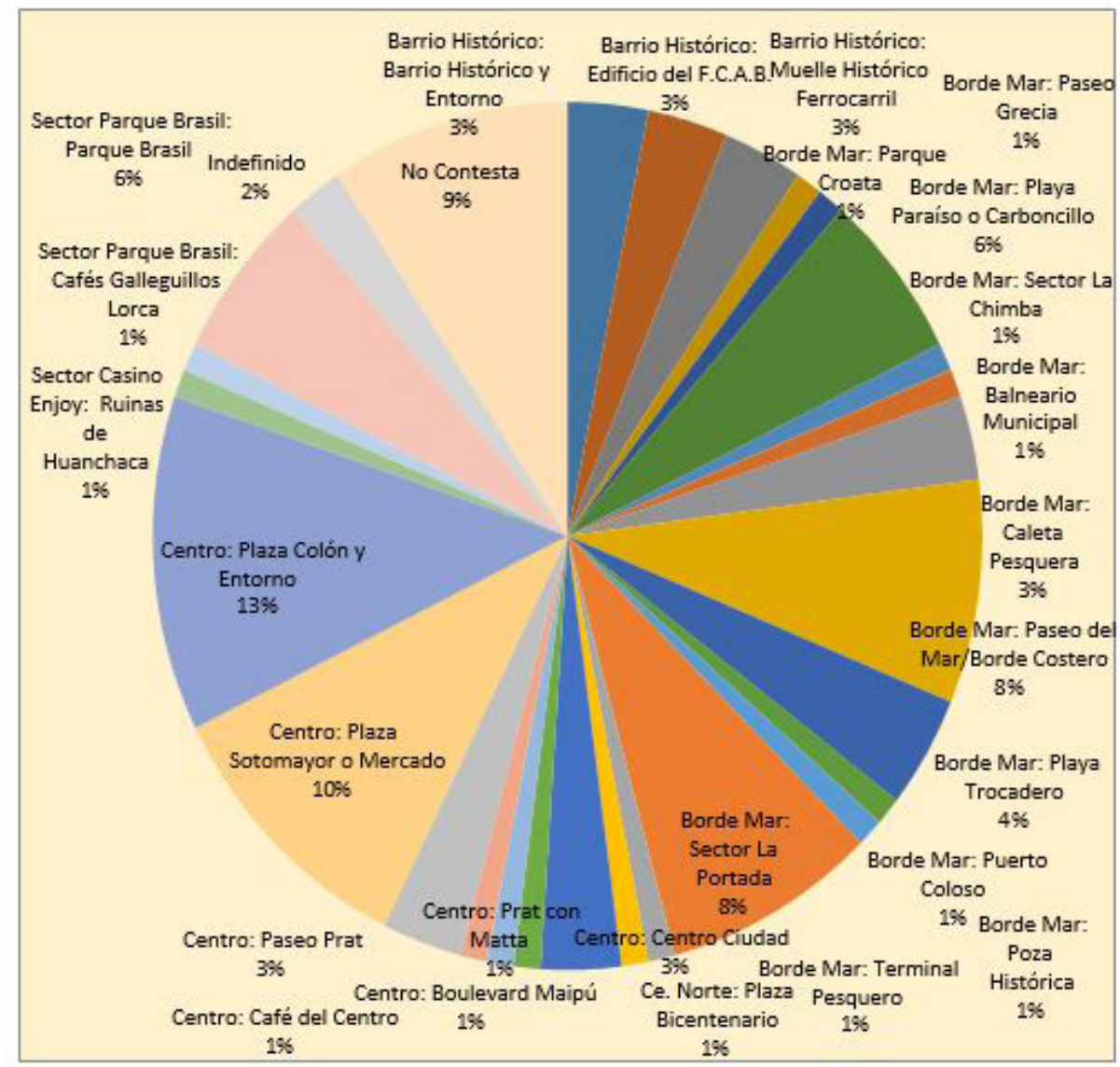

Fuente: Datos consulta ciudadana (Gebauer, 2015:384) 
Figura 2. Mapas mentales residentes locales en consulta ciudadana, respecto de elementos relevantes del centro histórico y ciudad Antofagasta_diciembre de 2012_2
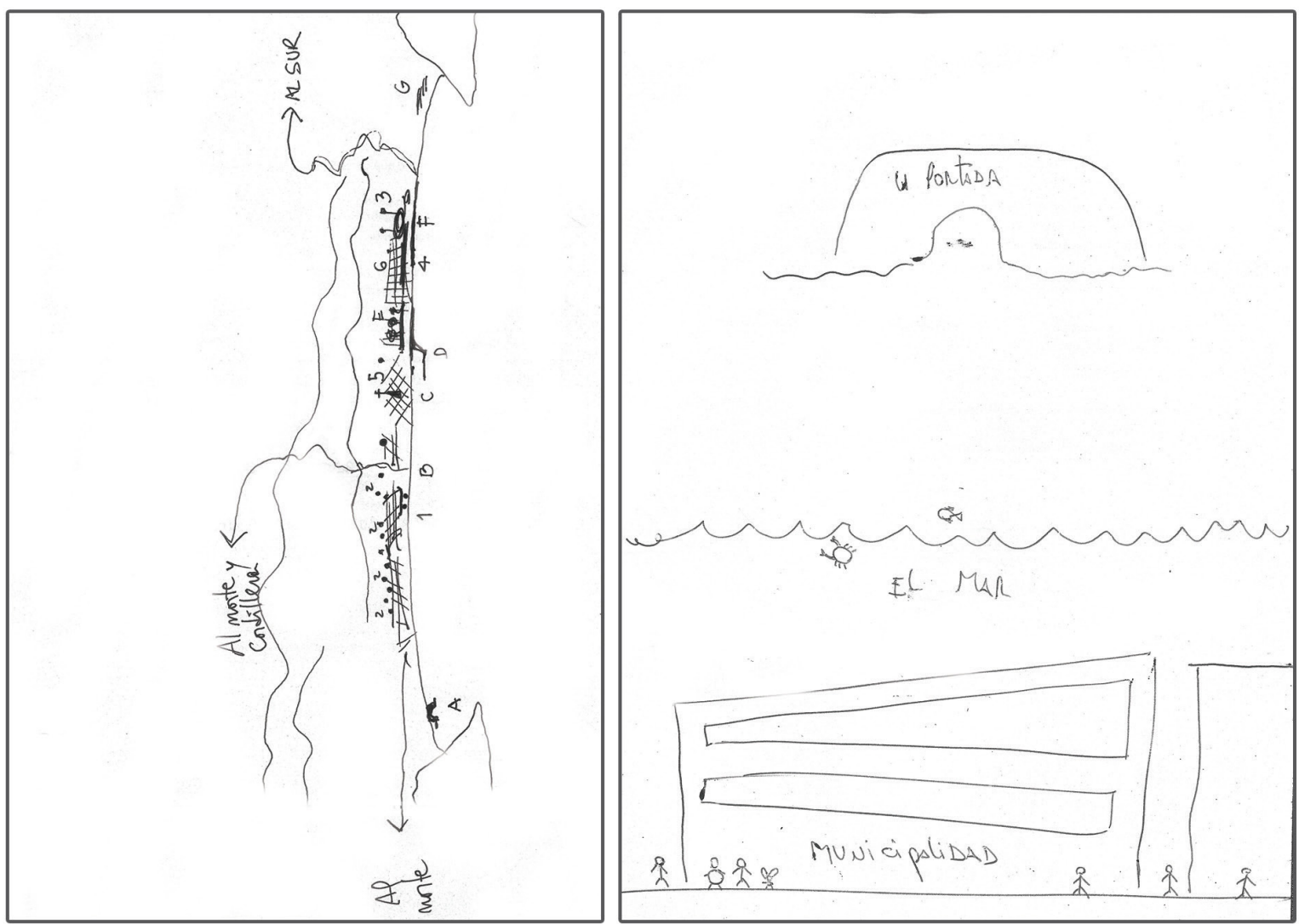

Fuente: Mapas mentales (Gebauer, 2015:388)

en la "consulta ciudadana”. Sin embargo, en temas relativos a la actividad y complementariedad de servicios, que un lugar de proyección internacional requiere y que el residente local demanda, éste ha sido escasamente implementado como espacio público y se reclama que en ello debiera considerarse la intervención mancomunada del sector público y privado para resolverlo.

Otro asunto a destacar es que, en todas estas consideraciones, lo que el transeúnte visualiza es una totalidad, puesto que en su experiencia no aparece un hecho puntual sino más bien su percepción acumulada de vivencias de la ciudad que no separa, al referirse a un lugar específico, sino que las incluye como parte de su acontecer de vida.

\subsection{Calles "sendas"}

La Gráfica $N^{\circ} 3$, incluye las calles de Antofagasta señaladas como importantes, por habitantes consultados, y que corresponden a "sendas" en las categorías de Lynch referidas, en que el residente distingue las calles que son estructuradoras del centro de la ciudad. Se destaca, por una parte, la estructuración de calles del centro y sus extensiones estructurantes, y por otra, la importancia de Avda. Costanera, borde-costero y Avda. Circunvalación, en el borde-cerro, que dan cuenta de la extensión longitudinal de la ciudad, al mismo tiempo que, entre ellas, dan cuenta de su dimensión y medida transversal.

En específico:

- Del casco central se señalan todas sus calles, destacando por el número de respuestas, Calle Prat, seguido por Avda. Matta y Calle Maipú. En los tres casos se trata de calles peatonales en que se concentra la mayor actividad del $\mathrm{CH}$.

- Con respecto a extensiones, se indican tanto las calles y avenidas que estructuran la 
extensión longitudinal del centro al norte, en Avdas. Pedro Aguirre Cerda y Bonilla, como al sur Avdas. Argentina, Brasil y Angamos. Estas vías dan cuenta de los ejes tentaculares señalados al definir el CHA.

- Con respecto a vías que estructuran longitudinalmente los bordes de la ciudad, se señalan tanto Avda. Costanera, con sus distintas nominaciones a lo largo del bordemar, como Avda. Circunvalación que da cuenta del borde-cerro. Marcan entre ellas la medida de la ciudad entre mar y cerro, consolidándose ambos como elementos identitarios de la misma.

- Se señala también Avda. Salvador Allende, que recorre transversalmente la ciudad, entre mar y cerro, en el sector más ancho de la misma, que es el eje de acceso a la ciudad desde la Pampa Salitrera y Desierto de Atacama, dando cuenta también de la dirección en que la Región Antofagasta tiene su mayor riqueza, que es donde se encuentran sus principales recursos singulares: mineros, antropológicos y astronómicos.
Con el conjunto de estas gráficas, imágenes y respuestas, a la consulta ciudadana, se logra establecer la imagen que tiene el habitante de su ciudad y los aspectos de paisaje que interesan, que para Antofagasta son de vital importancia, especialmente por la pregnancia de su territorio. Así mismo, se ratifica la imagen de ciudad entregada por el análisis morfológico desarrollado como dimensión tres, de la investigación de referencia y, en especial, dan cuenta de la extensión del centro de la ciudad a partir de sus ejes estructurantes que constituyen los ejes tentaculares de crecimiento del $\mathrm{CH}$ en su condición de ampliado.

\section{SEGUNDO APRONTE: ESTRUCTURA DE PAISAJE DEL CH Y CIUDAD ANTOFAGASTA IDENTIFICADO POR PERSONEROS ENTREVISTADOS}

La estructura de paisaje del $\mathrm{CH}$ y ciudad Antofagasta, identificada por profesionales y agentes del desarrollo urbano entrevistados, se abordó, como se indica al referirse a metodología, a partir del trabajo de campo iniciado en
Gráfica 3. Calles

de Antofagasta

percibidas como

importantes según

consulta ciudadana,

diciembre 2012

Fuente: Datos consulta ciudadana (Gebauer, 2015:389)

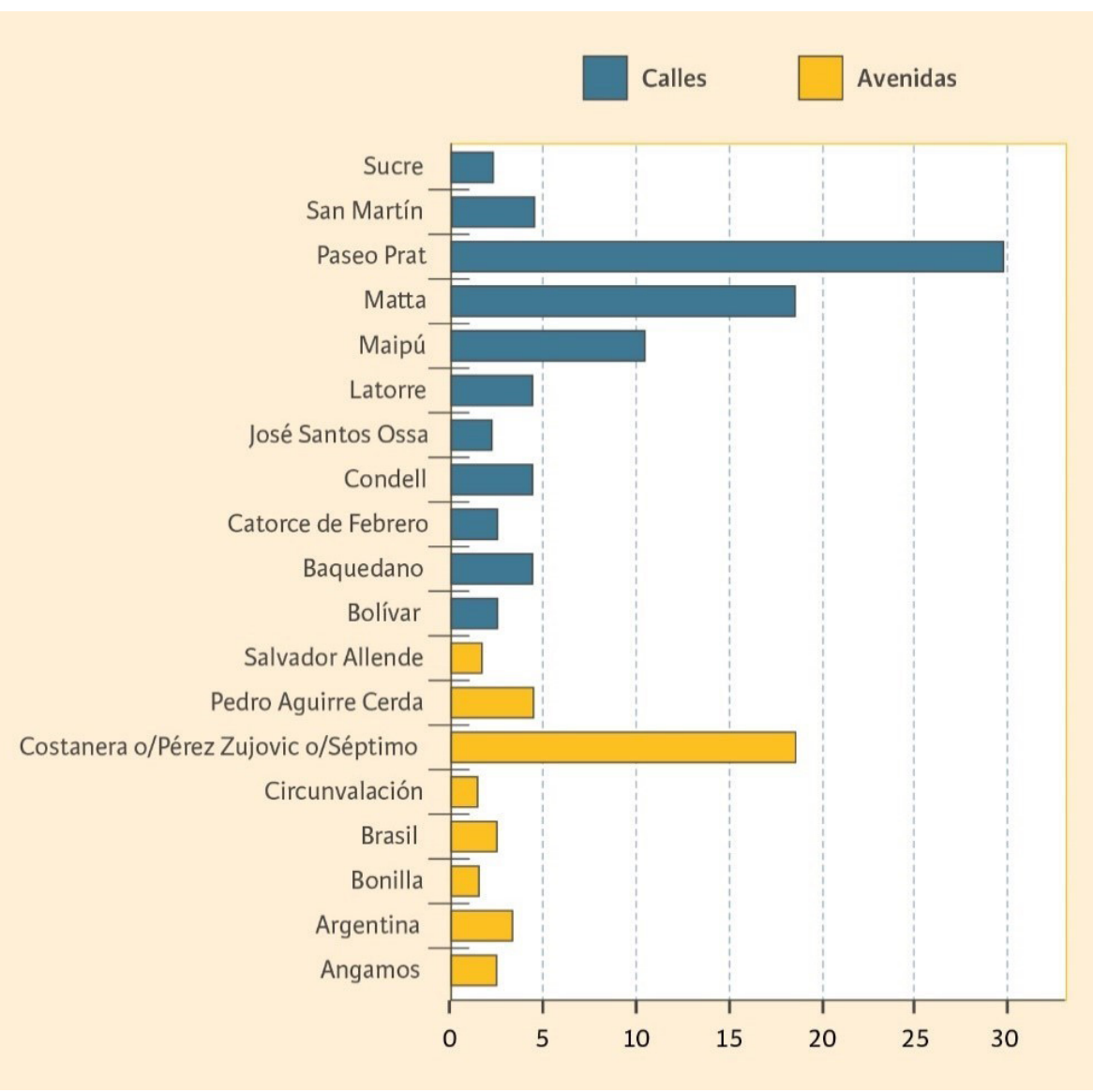


Antofagasta en abril de 2012, por quién suscribe, y desarrollado como "entrevista sistemática y a profundidad", el segundo semestre de 2012. Para este apronte se sistematizaron las respuestas dadas a pregunta $\mathrm{N}^{\circ} 4$ de la entrevista aludida, formulada en los siguientes términos:

\section{¿Qué de particular ofrece la ciudad de Antofagasta y su región?}

Las respuestas dadas por los entrevistados, en su mayoría, se refieren a territorio y paisaje, lo que hace retomar lo planteado por Joan Nogué i Font (2008 y 2009), quién destaca el paisaje como parte de la construcción cultural de una sociedad y por lo mismo, éste dice de su identidad.

Aparecen entre comillas y cursiva las citas textuales del/la entrevistado/a destacando los siguientes aspectos:

2.1 Geomorfología de la ciudad, en la que aparece, en su condición paisajística, el hecho de estar en el desierto más árido del mundo. En ello se destacan observaciones de entrevistados como: "disposición geomorfológica muy atractiva que es esta caída libre al mar, en que desaparece la ciudad y está siempre presente el horizonte"; " las montañas están muy cerca, la sequedad del panorama y desarrollo entre montaña y mar, es propio de esta ciudad"; "riqueza escenográfica increíble que ha sido reconocida por el cine y la publicidad"; y por otra parte, "la gran abertura, el espacio libre de la mirada" que ofrece una visión permanente del mar desde cualquier punto de la ciudad, unido a "escasa distancia entre cerro y mar que acota a la ciudad", y en su transversalidad, entrega su medida.

2.2 Condiciones climáticas estables todo el año, cercano al nivel de confort de $18^{\circ} \mathrm{C}$ que permitiría fomentar el turismo de intereses especiales porque se puede disfrutar de estos lugares en tiempos en que, los países del norte global, tienen temperaturas muy bajas. Así mismo, hace posible promover el turismo orientado a gente mayor, en expresión de un entrevistado, "el clima es uno de los grandes factores atractivos, y lo sería más si se lo potenciara para gente jubilada y mayor".

2.3 Atractivos naturales de interés turístico especial, que al no ser un factor de atracción de público masivo, resulta positivo porque son lugares de mucha fragilidad que debieran visitarse de forma dosificada, para que se conserven en sus condiciones de origen. A nivel turístico se cuenta, en la Región, con "tres circuitos turísticos de interés: Circuito Costero; circuito Salitrero y Desierto; y de Arqueología y Altiplano", sin embargo, estos no han sido implementados ni equipados. A nivel de ciudad "se cuenta con dos monumentos de relevancia: Ruinas de Huanchaca y La Portada", nuevamente se combina lo artificial y lo natural, "e hitos actuales, como son las Playas Artificiales."

2.4 En la actividad económica se destaca la Minería como soporte regional, y el desarrollo que ha tenido este sector desde años 1980 en adelante, con la llegada de Minera Escondida, lo que posibilita, que se apele a Antofagasta "como potencial centro de negocios que dice relación con el avance de inserción tecnológica que ha tenido la Región".

2.5 Existencia de energía natural disponible, como la solar y la geotérmica, de tal modo que " $a$ nivel Regional la existencia de Energía Geotérmica podría abastecer todo el Cono Sur" de América.

2.6 Lugares de encuentro masivo, que se destacan comoun hechoque está ocurriendo apartir del año 2005, "por recientes intervenciones: Sitio Cero del Puerto al costado del Mall; el concurso para recuperar las Ruinas de Huanchaca, frente a Enjoy; Parque Bicentenario; Plaza Anfiteatro en Nicolás Tirado; Playas Artificiales: Trocadero y Renovación del Balneario, que hacen que haya mejorado la calidad de vida urbana", como declara un entrevistado.

2.7 Falta de actividades complementarias al sector minero, dado que, "como ciudad ofrece poco en su calidad de vida, a pesar del ranking económico".

2.8 Borde costero y playas artificiales, "combinando aqui tanto elementos naturales, como es el borde-mar, como construidos por la ciudad, como son las playas artificiales".

Con respecto a las playas artificiales estas se fundan en esta presencia del mar y en el hecho de tener un clima benigno todo el año que justifica una inversión que otorga un servicio democrático a toda la ciudad. Los entrevistados las destacan como algo único de esta ciudad, en expresiones como "son un atractivo de la ciudad"; es importante y propio de esta ciudad "la generación de Playas Artificiales y recuperación del borde como espacio público”. Junto con ello se destaca 
que "en Antofagasta se juntan el Desierto más árido del mundo que se une con el mar, que por su sistema oceánico y llegada de la Corriente de Humboldt, en profundidad, hace que el mar sea de gran riqueza en flora y fauna, "es una selva" y eso nadie lo valora, ni comenta".

Concluyendo, los entrevistados, profesionales y agentes urbanos de la ciudad, señalaron el borde-mar, como la "plaza pública" de la ciudad. Destaca en ello que para el habitante local el borde cubre toda la extensión de la bahía y dice de la comprensión del Centro Histórico Ampliado de Antofagasta que, en sus elementos estructurantes, se extiende a todos los espacios que se consideran como parte de la identidad de esta ciudad y "el más extenso es su borde", que en expresión de uno de los agentes urbanos entrevistados, "se extiende hasta donde llega la mirada", esto dice de la configuración lineal de la ciudad de Antofagasta y de su clima y cielos limpios que permiten estas visiones extensas, y se abunda en ello al considerar que se tiene "el tesoro del mar". Junto con esta esencialidad hay aspectos importantes no resueltos así, "el borde-mar a lo largo de toda la ciudad es un atractivo, pero no está integrado el privado en las inversiones que se hacen en él, y habría que buscar un modo de incorporarlo."

\section{TERCER APRONTE: LUGARES QUE COMPROMETEN LA IDENTIDAD DE PAISAJE Y PROPUESTA}

A modo de propuesta futura se identifican los espacios, lugares y situaciones que se potencian como "interfase glocal", en el CHA de Antofagasta, destacándose entre ellos aquellos que dicen del borde-mar.

La investigación de referencia establece que uno de las condiciones para potenciar la inserción transnacional de la ciudad de Antofagasta y su Región, es hacer que los lugares que tienen potencial de trascender transregional, nacional o internacionalmente, se consoliden como tales. De allí que su especificación ayudará a visualizar el actual estado de desarrollo en que se encuentran, ya sea actualmente consolidados, en formación como tales, o potencialmente existentes.

Se privilegian aquellos lugares que teniendo condiciones morfológicas, consideradas relevantes en estudio de origen, estructura típica y atípica, tienen condiciones geográficas que dicen de elementos que los habitantes reconocen como propios de su ciudad y región como son: el mar; la confluencia en conjunto de cerro y mar; la conectividad longitudinal de la ciudad; su característica de territorio desértico, ya sea por

Figura 3. Muelles borde-costero centro Antofagasta y Playas Artificiales, vistos desde el sur-poniente

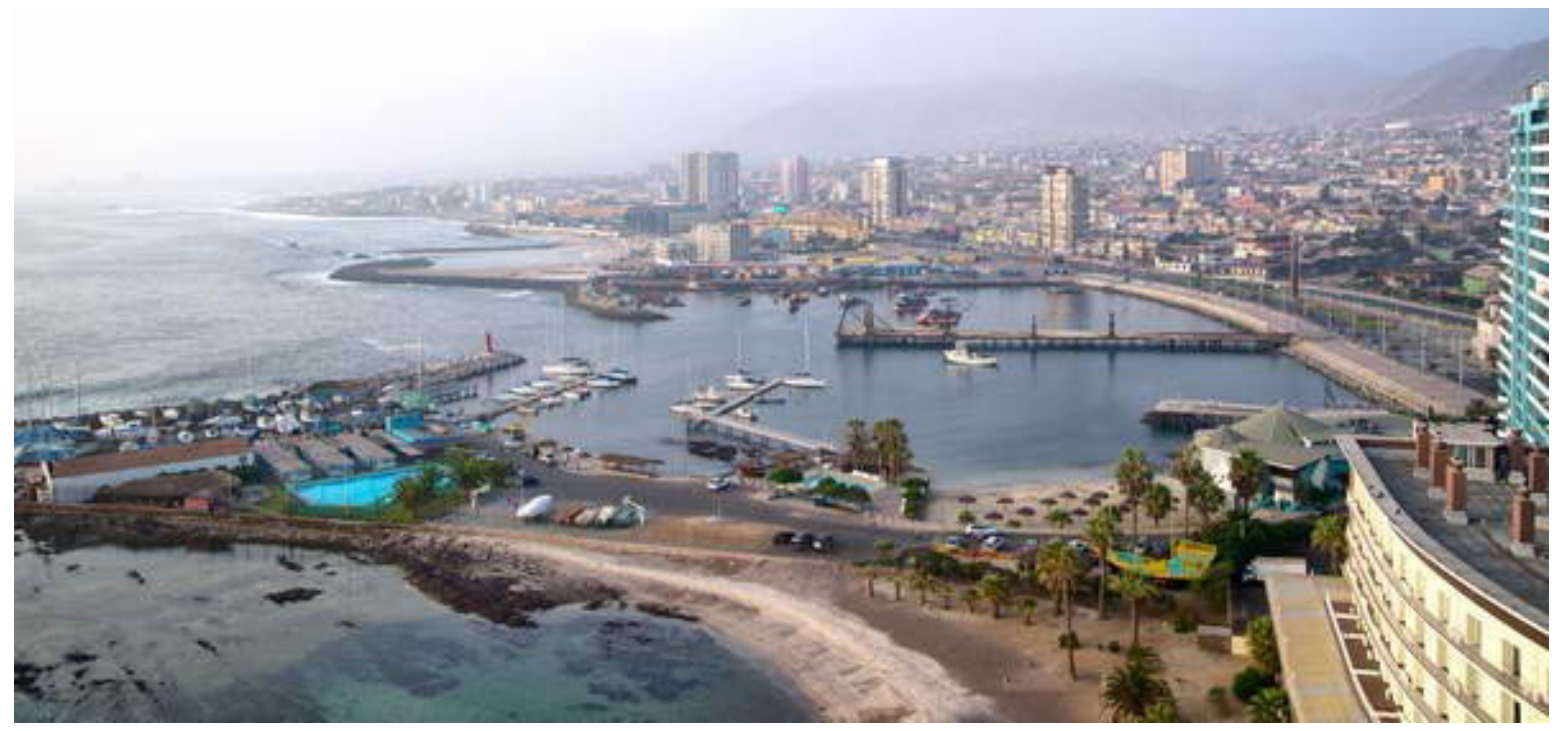

Fuente: Fotos Antofagasta en la web y Google Earth (2015) 
sus condiciones solares y eólicas, como por su territorio de base minera.

Se detectan y proponen los siguientes lugares específicos a estudiar, los que podrán ser ampliados o modificados, cuando se aborde su estudio en detalle:

3.1 Eje Transversal Ruinas de Huanchaca y entorno;

3.2 Eje entorno a Parque Japonés y Balneario Municipal y su continuidad transversal MarCerro en Calle Club Hípico, lugar que se mencionó como, "Cluster Parque Japonés, Estadio Regional, Balneario Municipal" por los entrevistados;

3.3 Avda. Angamos desde Parque Japonés a Ruinas de Huanchaca, incluido Casino Enjoy;

3.4 Edificios en altura en torno a Avda. Brasil desde su cabezal en Avda. Matta hasta Estadio Municipal y su correlato en borde-mar;

3.5 Eje Avda. Matta desde borde-mar a Calle Andrés Sabella;

3.6 Avda. Pedro Aguirre Cerda desde José Santos Ossa con Cementerio Municipal hasta Avda. Salvador Allende;

3.7 Modos de integración con Pedro Aguirre Cerda de Plaza de los Eventos;

3.8 Centro Histórico de Origen y su extensión entre borde-mar, Avda. Argentina y terrenos de FCAB contiguos por el norte de Calle Bolívar, y en particular lo que la investigación de origen definía como "Cluster cultural cívico-recreativo de origen" y "Cluster cultural-recreativo cívico en Plaza Sotomayor", en unidad con Mercado Municipal;

3.9 Desarrollo en torno a eje y patios del FCAB, que en su extensión en torno a su eje central es parte potencial de un eje de extensión tentacular del CHA.

3.10 Borde-Mar de extensión del Área Central desde edificios del Centro Histórico hasta Hipermercado Líder;

3.11 Borde-Mar en torno a Parque Croata y entre mar y Avda. Angamos;

3.12 Borde-Mar entre acceso Sur ciudad y Huáscar, y entre Huáscar y Coloso;

3.13 Borde-Mar en torno a llegada de Salar del Carmen al borde, a partir del eje Salvador Allende;

3.14 Borde-Mar en su conexión potencial entre Isla Guamán y La Chimba.
CUARTO APRONTE: DESARROLLO

FUTURO EN INTERVENCIONES

CONDUCENTES A CONSOLIDAR LOS

LUGARES ESTRATÉGICOS DE BORDE

Estos lugares se indican como estratégicos porque, actuar en ellos, interviniendo en un sector o área específica de los mismos, implica una acción de acupuntura porque ésta irradia al total de la ciudad en un efecto multiplicador (Cruz Gallach, 2008, Indovina, 2006; Steinberg, 2002, Esteban i Noguera, 1997). De los lugares indicados en 3er. Apronte, se seleccionan los que dicen del borde-mar o que arman un sistema entre éste y borde-cerro. En primera instancia se incluye el desarrollo del área Centro como GPU (Carrión, 2006), que aparece planteado por los habitantes como primera consideración de desarrollo para que la ciudad trascienda, pero resolviendo los problemas endémicos que contiene: usos degradantes, indefinición de su estructura vial y falta de recuperación de su estructura física. Esta última es necesario que se logre al integrar los sistemas borde-mar y borde-cerro que son parte de la estructura de potencial trascendencia internacional de Antofagasta.

Se señalan los siguientes lugares a desarrollar como "interfase glocal", que en su conjunto permitirían constituir el borde como un Gran Proyecto Urbano (GPU) y con ello asegurar su trascendencia. Se indican a modo de ejemplo a seguir, los siguientes Proyectos Estratégicos:

\subsection{Eje transversal Ruinas de Huanchaca que} se consolida como "interfase glocal"

Las Ruinas de Huanchaca, lugar que se ha ido, progresivamente, consolidando como "interfase glocal" (Gebauer, 2015). Geográficamente es el lugar, en Antofagasta, donde la Cordillera de la Costa, a través de esta Ruina, se une con el mar, por lo que allí la relación cerro-mar propia de este asentamiento se hace dramáticamente presente otorgándole, desde el inicio, una singularidad. La instalación de Industria Fundición de Plata, Huanchaca, de la que quedan explanadas y basamentos construidos en piedra extraída de la cantera cercana, es una obra arquitectónica e ingenieril que da cuenta de la particularidad del lugar al hacer emerger el territorio y la vastedad del paisaje local, en toda su magnitud, a lo que los entrevistados hacen referencia. Así mismo, 
Figura 4. Foto Sector Ruinas Huanchaca y Corte publicado en Concurso Plan Maestro
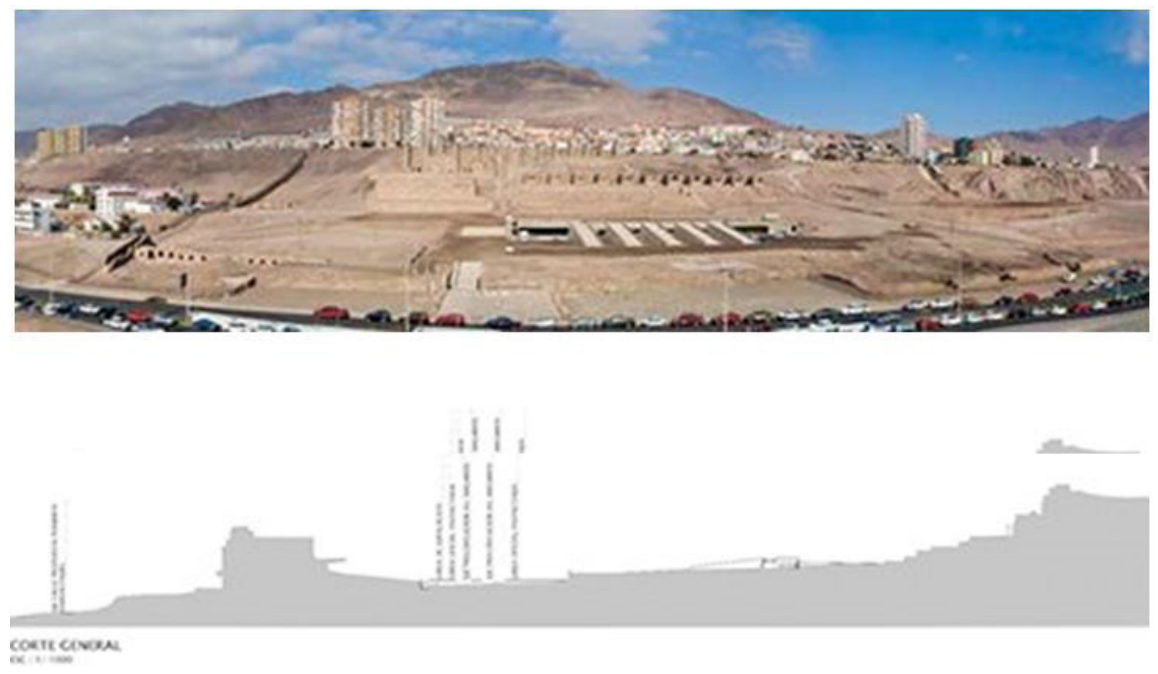

Fuente: Foto y Corte esquemático. @Fundación Ruinas de Huanchaca (2014)

el Proyecto Museo del Desierto (2009), se une a la condición propia del lugar y da la pauta para su reinterpretación contemporánea. Más aún, el Plan Maestro, seleccionado por concurso, el año 2013, consolida esta postura e incorpora en su propuesta de infraestructura edilicia, los espacios necesarios que permitirán se otorgue sustentabilidad a la oferta de espectáculos recreativo-culturales masivos que desde tiempo se vienen dando en estas explanadas, pero sin el equipamiento indispensable para que un evento de esta naturaleza trascienda transnacionalmente.

\subsection{Imágenes de Lugares tanto de Antofagasta como su Región que son parte de la identidad tanto del CHA como de la Región Antofagasta Ampliada}

Estas imágenes, junto con traer a presencia el territorio, que dice de elementos de identidad que otorgan particularidad a la Región y por ello aportan desde lo local, comolo es su mismodesierto que dramáticamente aparece en conformaciones naturales de sal como Farellones de Tara y Valle de la Luna, en su productividad y proyección económica se insertan en lo global, como son la actividad minera, los recursos arqueológicos y antropológicos de una cultura ancestral viva como es la "cultura atacameña", en San Pedro de Atacama y su entorno; las instalaciones astronómicas de Paranal, como así mismo de Proyecto ALMA en el Desierto de Atacama.
Al mismo tiempo se incorporan los lugares que dan identidad en el borde-costero y que trascienden a la Región, como son La Portada; Farellón de borde Costero; y Muelle Histórico de Ferrocarriles, hoy remodelado y abierto al público, que articula con la Poza Histórica al Sur, que en la Plazoleta del ex Resguardo Marítimo que enfrenta a Calle Bolívar marca el inicio de la ciudad en el borde-mar, que requiere ser señalado, y que a través de Caleta Pesquera Antofagasta se une hacia el Norte (ver Figura $N^{\circ}$ ).

\subsection{Potencial desarrollo del Borde Emergente como "interfase glocal"}

Se reconoce que, si el borde costero de construcción en altura que tiene una imagen global, se relaciona transversalmente con cada sector aledaño interior, que tienen una configuración local, se lograría potenciar este rol de "interfase glocal" (ver Figura $N^{\circ}$ ). Es el caso del área del FCAB al Oriente de Caleta Pesquera Central; o el borde-mar, al sur del Puerto de Antofagasta unido al rol de configuración local de Avda. Brasil, interactuando a través de crear un primer nivel o piso noble más abierto que consolide el espacio público y potencie, en las intervenciones inmobiliarias, del Parque Brasil y borde-mar en esta área, el acoger actividades de índole recreativo y cultural incluidas aquellas gastronómicas sofisticadas, aprovechando lo que se está dando con restaurantes de comida peruana, mexicana, china y otros, otorgando, a través de ello, una ampliación de 
Figura 5. Imágenes identitarias del CH Ampliado (CHA) y ciudad-región Antofagasta

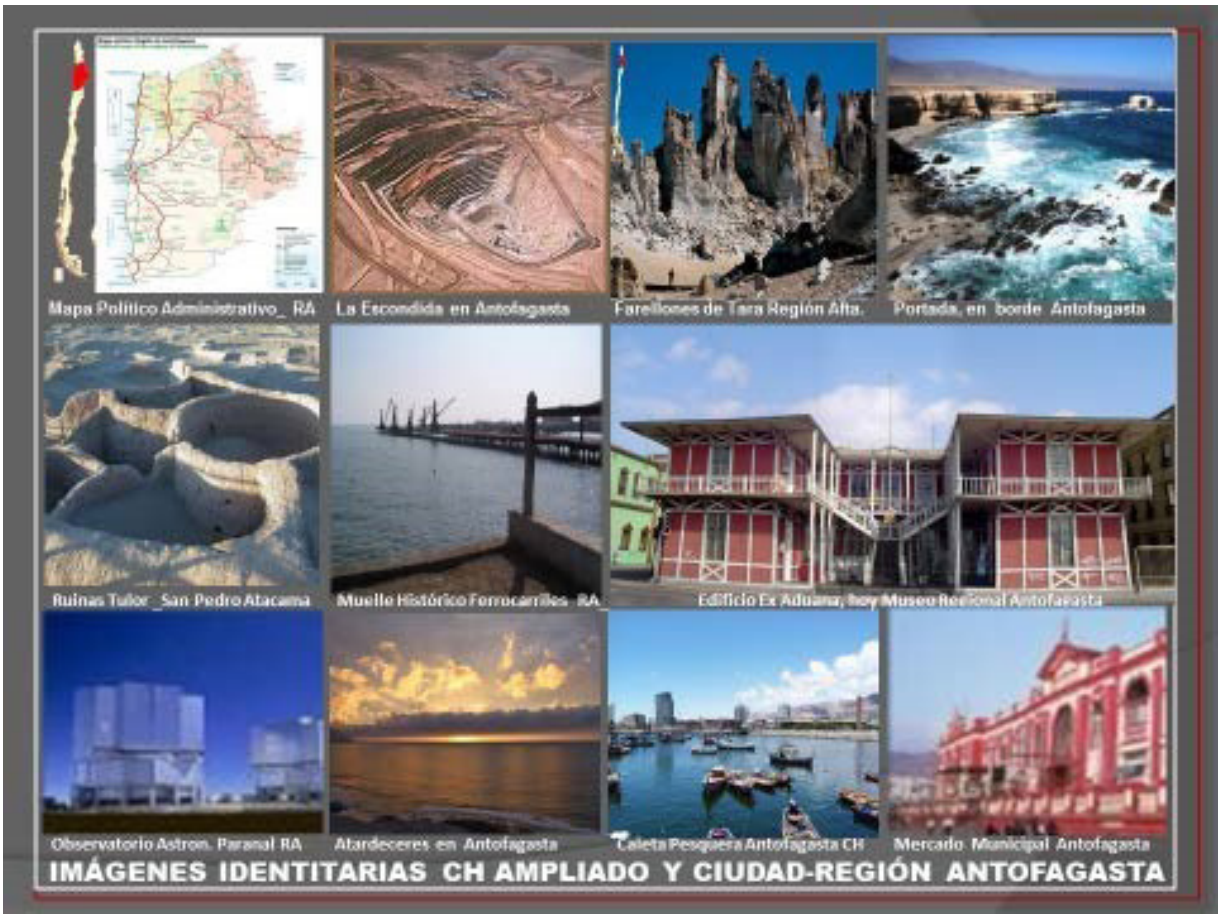

Fuente: Collage fotográfico (Gebauer, 2015:417)

Figura 6. Potencial desarrollo de "interfase glocal" en la relación borde-mar e interior en interacción con Avda. Brasil

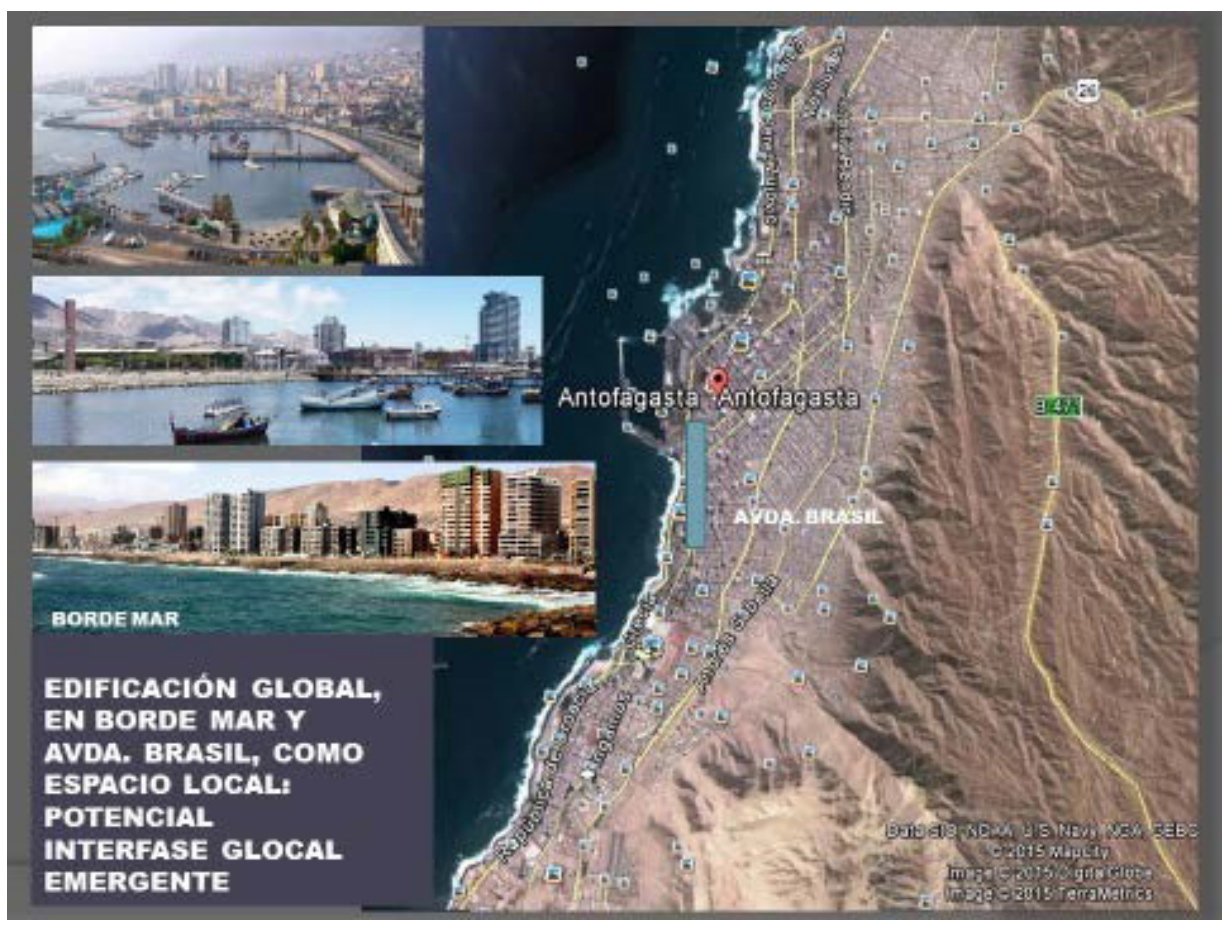

Fuente: Collage elaboración propia en base a fotos Antofagasta en la web y Google Earth 
la participación local del migrante.

Para potenciar estos lugares, en su rol de "interfase glocal", se requiere de una acción mancomunada público-privado de clara orientación hacia una imagen de ciudad, por parte del Sector Público, que asegure una acción privada inmobiliaria conducente a hacer realidad la ciudad que se busca promover transnacionalmente, incorporando siempre los valores locales y la comunidad local.

\subsection{Acontecimiento glocal que se proyecta al borde-mar en área central desde el interior del Centro, en entorno cultural Plaza Colón y FCAB}

La Figura $N^{\circ} 7$ da cuenta del acontecimiento glocal, en este caso, al integrarse un espectáculo global como fue el de las máquinas voladoras, espectáculo circense traído desde Europa en 2010, expuesto en un pasa-calles desde la explanada del FCAB en un recorrido en torno a Plaza Colón, saliendo al borde por Calle Prat y regresando por Calle Bolívar. Lo local, en este caso, es el espacio del Barrio Histórico y el entorno Cultural de Plaza Colón que se reconoce como espacio público de la ciudad, y lo global es el espectáculo circense, generándose por la interacción de ambos, junto al público asistente, el "acontecimiento glocal".

\subsection{Borde-Mar como "interfase glocal"}

El borde-mar, como se expresa en Figura $N^{\circ} 8$, es parte de la identidad de la ciudad, como se ha mencionado a lo largo de este escrito, y se constituye en la "plaza pública" de la ciudad haciendo presente su importancia local. Sin embargo, cualquier espectáculo masivo que en él ocurre, sea regional, nacional o internacional, trasciende a la Región, y por lo mismo aparece allí el "acontecimiento glocal".

A su vez, a lo largo de este borde existen lugares que por su singularidad geográfica o por las intervenciones realizadas en ellos, se potencian como "interfase glocal" que en general son lugares con gran riqueza escénica tales como: Caleta Coloso; Ruinas de Huanchaca antes mencionada; Parque Japonés y entorno; Muelle del FCAB y Barrio Histórico; Caleta Pesquera Central, Playa Paraíso y Consistorial; Trocadero, su Playa Artificial, Isla Guamán y La Chimba; La Portada, su entorno y Museo; todos los cuales si se los interviene adecuadamente se constituirían en nodos o polos de atracción en el borde.

Figura 7. Acontecimiento glocal en Centro de Antofagasta y su proyección al borde-mar

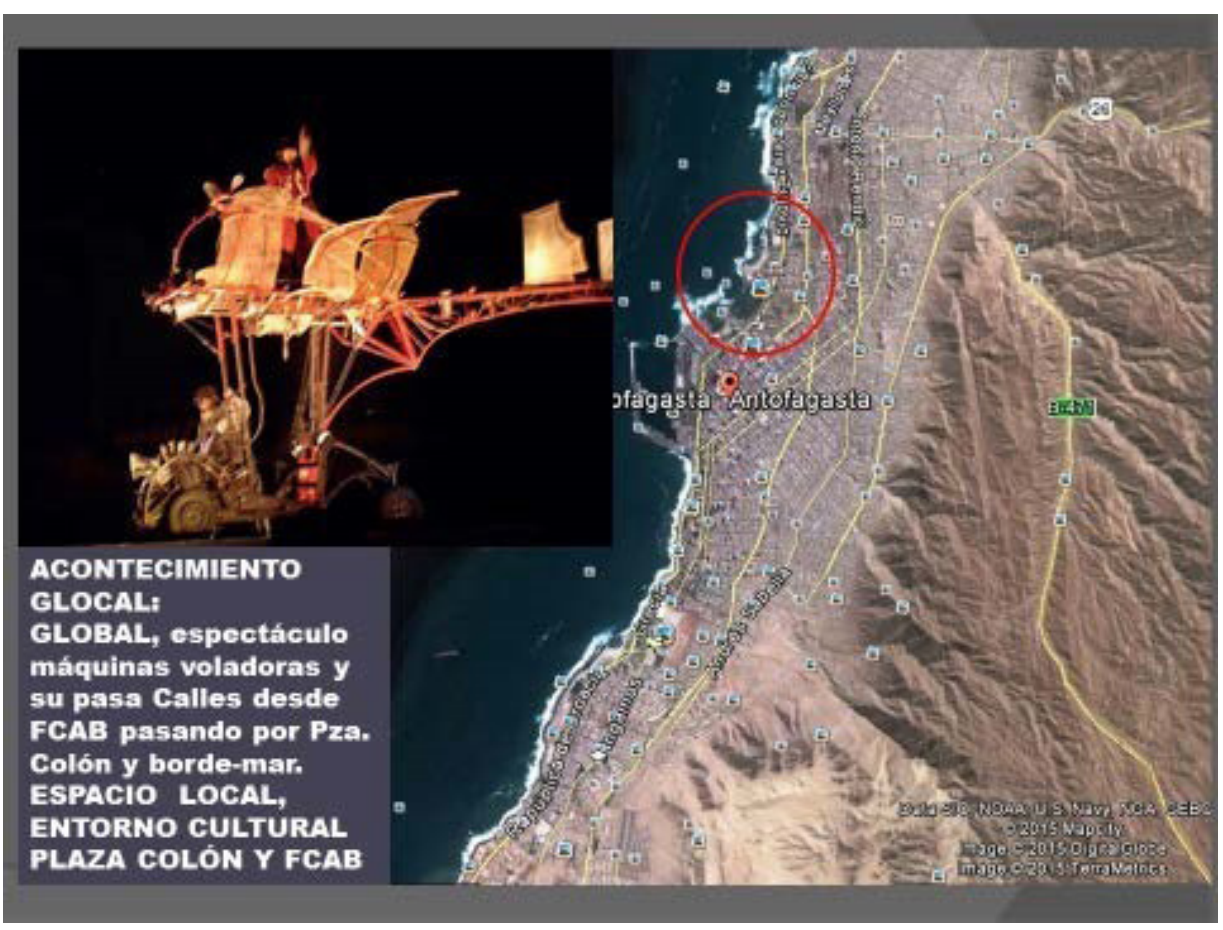

Fuente: Elaboración superponiendo fotografía archivo propio (2010) e imagen foto aérea Antofagasta Google Earth (2015) 
Figura 8. Borde-Mar como "interfase glocal” en lugares específicos

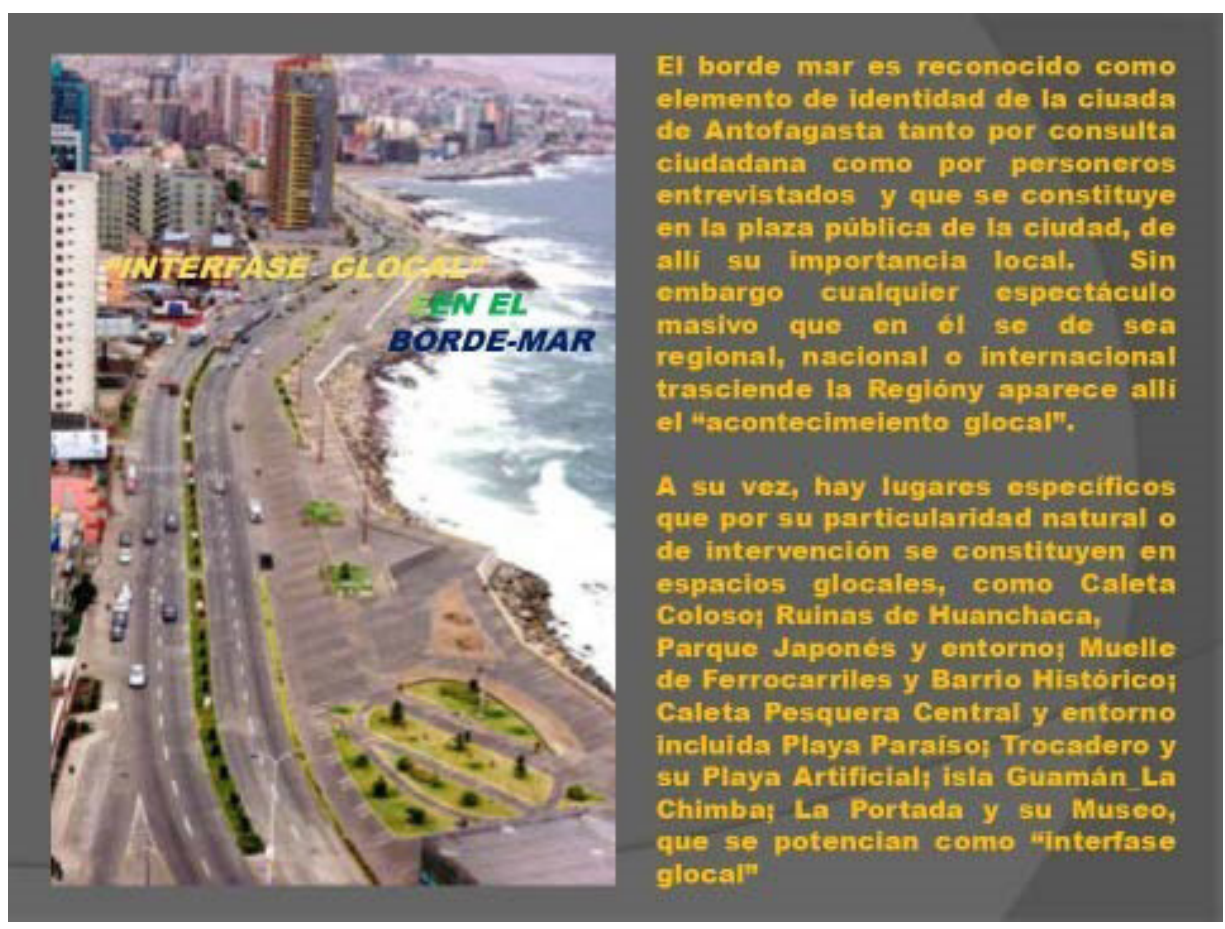

Fuente: Elaboración propia tomando como base foto Plan Bicentenario Región Antofagasta, Directorio Ejecutivo Obras Bicentenario II Región (2005)

A partir de estos focos y de estudiar los usos de estos lugares de acuerdo a lo planteado en 1er. y 2 do. Aprontes de este artículo, junto con visualizar y proponer su diseño estratégico, se puede desarrollar el total del borde-mar como "interfase glocal" por la dimensión única que exhibe que hace que siempre se visualice la totalidad del paisaje a la vez que la parte, es decir el lugar cotidiano y específico en que uno se encuentra, lo que permite que esta superposición y simultaneidad de escalas propia del "espacio glocal" aparezca y con ello tener el soporte que da cabida al "acontecimiento glocal" Abordarlo en esta dimensión, como GPU permitiría dar un desarrollo sofisticado de nivel internacional al borde, que al mismo tiempo de mejorar la calidad de vida local de la ciudad, hiciera de éste el primer lugar para potenciar la inserción transnacional de Antofagasta lo que, al realizarse, se convierte en un catalizador para que el resto de las propuestas planteadas se implementen. $\mathbf{C}$

\section{REFERENCIAS BIBLIOGRÁFICAS}

Besse, Jean-Marc (2000). Voir la terre. Six essais sur le paysage et la géographie. Arles: Actes Sud.
Borja, Jordi \& Castells, M. (1997). Local y Global. La Gestión de las ciudades el la era de la de la informática. Barcelona: Taurus.

Brandâo, Pedro (2011). La imagen de la ciudad: estrategias de identidad y Comunicación. Barcelona: Universitat de Barcelona Edicions. España.

Carrión, Fernando (2002). El regreso a la Ciudad Construida.

(2006). Centro Histórico como Proyecto y Objeto de Deseo. Quito: FLACSO.

Castells, Manuel (1997). La era de la información: economía, sociedad y cultura (3 vols.). Madrid: Alianza Editorial, (1ra. edición 1996).

(2001). Centros Históricos de América Latina y Caribe. Quito: UNESCO/ BID/ SIRCHAL.

Cruz Gallach, Helena (2008). "El Auge de los Planes Estratégicos y los Proyectos Urbanos: Hacia un Planeamiento Urbanístico Consensuado", en Diez años de cambios en el Mundo, en la Geografía y en las Ciencias Sociales, 1999-2008. Actas del $X$ Coloquio Internacional de Geo-crítica. 
Actas del X Coloquio Internacional de Geografía Crítica. Barcelona: Universidad de Barcelona, 26-30 de mayo de 2008. Barcelona. España.

De Mattos, Carlos (1999). "Santiago de Chile, globalización y expansión metropolitana: lo que existía sigue existiendo", en EURE: Revista Latinoamericana de Estudios Urbanos y Regionales, Vol. XXV, $\mathrm{N}^{\circ} 76$, Santiago de Chile, dic. 1999. Santiago de Chile: EURE.

(2002). "Transformaciones de la Ciudad LA ¿Impactos de la Globalización?” en Revista Eure. Santiago, Chile: vol.XXVIII, número 85, dic. 2002, pp 11-29. DOI: $10.4067 / \mathrm{S} 0250-71612002008500001$. Santiago, Chile

Esteban i Noguera, Juli (1999). "Pla Urbanistic versus pla estratègic", en Quaderns de la Societát

Catalana d'Ordenació del Territori, 1999, $\mathrm{N}^{\circ}$ 9, pp.87-101. Barcelona: Quaderns. Barcelona. España.

Garcés Feliú, E., O'Brien, J. \& Cooper, M. (2010). "Del asentamiento minero Chuquicamata (Chile) y la contribución de la minería a la configuración del territorio y el desarrollo social y económico de la Región de Antofagasta durante el siglo XX". En Revista EURE v.36 n.107. Santiago de Chile: Instituto Estudios Urbanos. Pontificia Universidad Católica de Chile.

Gebauer Muñoz, María Adriana (2015). Centro Histórico como interfase glocal para la inserción de la Ciudad Intermedia en el Sistema Global de Ciudades: Caso de estudio Antofagasta, Chile, 1990/2012. Tesis Doctoral defendida y aprobada 23 Enero 2015 con calificación máxima. Universidad de Guadalajara, Guadalajara, México.

Giddens, Anthony (2008). "Vivir en una sociedad postradicional" en U. Beck, A. Giddens \& S. Lash: Modernización reflexiva: Política, tradición y estética en el orden social moderno. Madrid: Alianza Editorial

Gifreu, Josep (1991). Estructura general de la comunidad pública. Barcelona: Pórtic.

González, Sara (2005). "La geografía escalar del capitalismo actual", en Geo Crítical Scripta Nova. Revista electrónica de geografía y ciencias sociales. Barcelona: Universidad de Barcelona, 15 de mayo de
2005, vol. IX, núm. 189. http://www.ub.es/ geocrit/sn/sn-189.htm [ISSN: 1138-9788].

Habraken, N. John (1979). El Diseño de Soportes. Barcelona: Editorial Gustavo Gili.

Heidegger, Matín (2009). El Arte y el Espacio, traducción de Jesús Adrián Escudero. Barcelona: Herder Editorial.

(2010). La Metafisica del Espacio: El Encuentro de Heidegger con Chillida. Barcelona: Herder Editorial.urbano e pianificazione di área vasta". En Revista Archivo di Studi Urbani e Regionali, pp: 49-71. ISSN: 0004-0177. Milano, Italia.

Lynch, Kevin (1984). La imagen de la ciudad. Barcelona: Gustavo Gili. Barcelona, España.

(2013). La Imagen de la Ciudad. ISBN: 978-84-252-1748-7. Barcelona: Editorial Gustavo Gili SL, GG Reprints. Barcelona, España.

Martínez, Carlos \& Arrarás, Caro (2013). “Derivas de la memoria. Una biocartografía de Madrid:Indagación en las metodologías de comprensión de la ciudad desde la experiencia subjetiva", en Arte y Ciudad. Revista de Investigación 2013,-Junio-n ${ }^{\circ} 3$ (1), Extraordinario, pp. 471-490, ISSN 2254-2930.

Muñiz, Norberto (2007). "Marketing de ciudades: de la gestión estratégica y de infraestructuras a la creatividad y los valores". En Antonio Baladrón y otros, Publicidad y ciudad. Sevilla: Zamora, Comunicación Social.

Narváez Tijerina, Adolfo Benito (2010). La morfogénesis de la ciudad: Elementos para una teoría de los imaginarios urbanos. Monterrey: Universidad Autónoma de Nuevo León.

(2011). Etnografia para la investigación en arquitectura y urbanismo. Monterrey Universidad Autónoma de Nuevo León.

Nogué i Font, Joan (2008). El paisaje en la cultura contemporánea. Madrid: Biblioteca Nueva. Madrid. España.

Nogué i Font, J. \& de San Eugenio Vela, J. (2009). "Pensamiento geográfico "versus" teoría de la comunicación: hacia un modelo de análisis comunicativo del paisaje", en Documents d'anàlisi geogràfica, $N^{o} 55$, pp: 25-56. ISSN: 2014-4512. URL: http:// revistes.uab.cat/dag Barcelona. España.

Ortega Cantero, Nicolás (2004). "Naturaleza y 
cultura en la visión geográfica moderna del paisaje" en Nicolás Ortega Cantero (ed.), Naturaleza y cultura del paisaje. Madrid: Ediciones de la Universidad Autónoma de Madrid.

Pesci, Rubén (1993). "La Interfase Urbana”, en Revista CA N43 Colegio de Arquitectos. Santiago, Chile.

(2010). Ambitectura. Buenos Aires. Argentina.

Rábago Anaya, Jesús (2006). El sentido de construir. Primera edición en español: Guadalajara, México: CUAAD, Universidad de Guadalajara.

Robertson, Roland (1992). Globalization: Social Theory and Global Culture. London: Sage. Rossi, Aldo (1992). La Arquitectura de la Ciudad. ISBN: 97884-252-16060. Barcelona: G.Gili.

Samuels, Ivor; Buraglia, Pedro; Calaskan, Olgu; Del Río, Vicente; Gebauer, M.A. y otros (2013). "ISUF Task Force on Research and Practice in Urban Morphology: An Interim Report", Urban Morphology. Enero 2013. Birmingham University, UK.

Sassen, Saskia (2003). "Localizando ciudades en circuitos globales". en Revista Latinoamericana de Estudios Urbanos Regionales, EURE, v.29, $\mathrm{N}^{\circ}$ 88, Santiago de Chile, Pontificia Universidad Católica de Chile, diciembre 2003.

(2010). "Cities in today's Global Age", en Social Science Report, Cap. 1. UNESCO.

Silva, Armando (2003). "Urban imaginaries from Latin America”, en Documents 11. Kassel: Cantz Editions.

Steinberg, Florian (2002). "Strategic Urban Planning in Latin America: Experiences of Building and Managing the Future", en IHS Making Cities work, SINPA NumberInternational, $N^{o}$ Flores, Silvia 22/ November 2002. Rotterdam

Taylor S.J. \& Bogdan, R. (1987). Introducción a los métodos cualitativos de investigación. Buenos Aires: Paidós, 2da. Edición. ISBN: 84-7509-816-9. URL: http://www.paidos. com. Buenos Aires. Argentina.

Varguillas C., Carmen y Ribot de (2007). "Implicaciones conceptuales y metodológicas en la aplicación de la entrevista a profundidad". En Laurus
Revista de educación, año 2007/vol.13, número 023: pp. 249-262. ISSN: 1315883X. Venezuela: Universidad Pedagógica Experimental Libertador.

Vidal Moranta, Tomeu \& Pol Urrútia, Eric (2005.) "La apropiación del espacio: una propuesta teórica para comprender la vinculación entre las personas y los lugares", en Anuario de Psicología 36, Núm. 3: pp. 281-297. ISSN: 0066-5126. Barcelona: Universitá de Barcelona. España. 